University of Nebraska - Lincoln

DigitalCommons@University of Nebraska - Lincoln

U.S. Environmental Protection Agency Papers

U.S. Environmental Protection Agency

2009

Evidence-based integrated environmental solutions for secondary lead smelters: Pollution prevention and waste minimization technologies and practices

\author{
A. M. Genaidy \\ University of Cincinnati - Main Campus, world_tek_inc@yahoo.com \\ R. Sequeira \\ University of Cincinnati - Main Campus \\ T. Tolaymat \\ U.S. Environmental Protection Agency \\ J. Kohler \\ U.S. Environmental Protection Agency \\ M. Rinder \\ WorldTek Inc.
}

Follow this and additional works at: https://digitalcommons.unl.edu/usepapapers

Genaidy, A. M.; Sequeira, R.; Tolaymat, T.; Kohler, J.; and Rinder, M., "Evidence-based integrated environmental solutions for secondary lead smelters: Pollution prevention and waste minimization technologies and practices" (2009). U.S. Environmental Protection Agency Papers. 101.

https://digitalcommons.unl.edu/usepapapers/101

This Article is brought to you for free and open access by the U.S. Environmental Protection Agency at DigitalCommons@University of Nebraska - Lincoln. It has been accepted for inclusion in U.S. Environmental Protection Agency Papers by an authorized administrator of DigitalCommons@University of Nebraska - Lincoln. 


\title{
Evidence-based integrated environmental solutions for secondary lead smelters: Pollution prevention and waste minimization technologies and practices
}

\author{
A.M. Genaidy ${ }^{\text {a,* }}$, R. Sequeira ${ }^{\text {a }}$, T. Tolaymat ${ }^{\text {b }}$, J. Kohler ${ }^{\text {c }}$, M. Rinder ${ }^{\text {d }}$ \\ a University of Cincinnati, Cincinnati, Ohio, USA \\ ${ }^{\mathrm{b}}$ U.S. Environmental Protection Agency, Office of Research and Development, Cincinnati, Ohio, USA \\ ' US Environmental Protection Agency, Office of Solid Waste and Emergency Response, Washington DC, USA \\ d WorldTek Inc, Cincinnati, USA
}

\section{A R T I C L E I N F O}

\section{Article history:}

Received 22 August 2008

Received in revised form 8 January 2009

Accepted 13 January 2009

Available online 20 February 2009

\section{Keywords:}

Lead

Pollution prevention

Waste minimization

Technologies

Practices

\begin{abstract}
A B S T R A C T
An evidence-based methodology was adopted in this research to establish strategies to increase lead recovery and recycling via a systematic review and critical appraisal of the published literature. In particular, the research examines pollution prevention and waste minimization practices and technologies that meet the following criteria: (a) reduce/recover/recycle the largest quantities of lead currently being disposed of as waste, (b) technically and economically viable, that is, ready to be diffused and easily transferable, and (c) strong industry interest (i.e., industry would consider implementing projects with higher payback periods). The following specific aims are designed to achieve the study objectives: Aim 1 - To describe the recycling process of recovering refined lead from scrap; Aim 2 - To document pollution prevention and waste management technologies and practices adopted by US stakeholders along the trajectory of LAB and lead product life cycle; Aim 3 - To explore improved practices and technologies which are employed by other organizations with an emphasis on the aforementioned criteria; Aim 4 - To demonstrate the economic and environmental costs and benefits of applying improved technologies and practices to existing US smelting operations; and Aim 5 - To evaluate improved environmental technologies and practices using an algorithm that integrates quantitative and qualitative criteria.

The process of identifying relevant articles and reports was documented. The description of evidence was presented for current practices and technologies used by US smelters as well as improved practices and technologies. Options for integrated environmental solutions for secondary smelters were introduced and rank ordered on the basis of costs (i.e., capital investment) and benefits (i.e., production increases, energy and flux savings, and reduction of $\mathrm{SO}_{2}$ and slag). An example was provided to demonstrate the utility of the algorithm by detailing the costs and benefits associated with different combinations of practices and technologies. The evidence-based methodology documented in this research reveals that it is technically and economically feasible to implement integrated environmental solutions to increase lead recovery and recycling among US smelters. The working example presented in this research can be confirmed with US stakeholders and form the basis for implementable solutions in the lead smelter and product industries to help reverse the overall trend of declining life-cycle recycling rates.
\end{abstract}

(O2009 Elsevier B.V. All rights reserved.

\section{Introduction}

In today's global economy businesses, consumers and communities are challenged more than ever with the continual significant increase in the costs of, among other things, doing business, daily living and upkeep of societal activities. In this endeavor, the practice of sustainable development becomes integral to maintain the delicate balancing act among the needs of business, society and environment.

\footnotetext{
* Corresponding author.

E-mail address: world_tek_inc@yahoo.com (A.M. Genaidy).
}

This research deals with the environmental management of lead which makes up the largest hazardous waste stream in the US. Approximately $88 \%$ of US production is used in the manufacture of lead-acid batteries (LAB) (Smith, 2008). Based on an exploratory study of LAB product lifecycle, Genaidy et al. (2008) found that the recycling rates for lead recovery declined from 1999 to 2006, with a peak of $85.2 \%$ in 1999 and significantly dropping to $66 \%$ in 2006 . According to the authors, the reasons for the decline was attributed to one or more of the following: (a) the amount of lead recovered was virtually unchanged and fluctuating in the range of 10010 and 1060 thousand tons; (b) the amount of lead in domestic battery consumption went up by $18 \%$ from 1995 to 2002 at an annual growth rate of $2.25 \%$; and 
(c) the amount of lead in imported batteries increased by $118 \%$, a value much higher than the $37 \%$ recorded for lead content in exported batteries. In lieu of the declining recycling rates, the focus of this paper is to explore environmental improvement strategies to increase lead recycling, process efficiency and recovery in order to improve human and environmental health as well as the bottom line of lead smelters, lead-acid battery and other lead product industries.

Environmental management has evolved over the years through a series of successive paradigms: (a) Passive environmental management; (b) Reactive environmental management or end-of-pipe approaches; (c) Proactive environmental management or cleaner production (Hilson, 2003). Passive environmental management included foul and flee (e.g., after contaminating a plot of land, one would abandon the area), dilute and disperse (e.g., the dispersal of waste in the atmosphere or water body, the only waste management practice in pre-industrial society), and concentrate and contain (emerged to address highly toxic wastes such as nuclear waste and spent fuels). End-of-pipe approaches involved the installation of purification and detoxification units at the end of emission pipes and coincided with the implementation of national environmental regulations. The concept of cleaner production has emerged in the past $10-15$ years. It embraces waste minimization and pollution prevention at the source, and combines environmental and business concerns.

A comprehensive review of electronic databases suggest general reviews exist on pollution prevention and waste minimization technologies and practices (e.g., Freeman et al., 1992; Chaaban et al., 2001; Moors et al., 2005; Hossain et al., 2008). However, efforts are fragmented on specific technologies and/or practices that address maximum lead recovery at the pre-processing or the in-processing stage (e.g., Reuter et al., 1997; Andrews et al., 2000). Given that the number of secondary lead smelter facilities dropped from 50 plants in 1995 (USEPA, 1995) to an estimated number of 21 plants in 2006 on the basis of data derived from the US Geological Survey (Carlin et al., 2006), there is a need to augment the production capacity of these fewer smelters to reverse the declining recycling rates, yet, to improve the environmental performance of the smelters.

An evidence-based methodology is adopted in this research to establish strategies to increase lead recovery and recycling via a systematic review and critical appraisal of the published literature. In particular, the research examines pollution prevention and waste minimization practices and technologies that meet the following criteria: (a) reduce/recover/recycle the largest quantities of lead currently being disposed of as waste, (b) technically and economically viable, that is, ready to be diffused and easily transferable, and (c) strong industry interest (i.e., industry would consider implementing projects with higher payback periods). The following specific aims are designed to achieve the study objectives: Aim 1 - To describe the recycling process of recovering refined lead from scrap; Aim 2 - To document pollution prevention and waste management technologies and practices adopted by US stakeholders along the trajectory of LAB and lead product life cycle; Aim 3 - To explore improved practices and technologies which are employed by other organizations with an emphasis on the aforementioned criteria; Aim 4 - To demonstrate the economic and environmental costs and benefits of applying improved technologies and practices to existing US smelting operations; and Aim 5 - To evaluate improved environmental technologies and practices using an algorithm that integrates quantitative and qualitative criteria.

\section{Recovering lead from waste streams}

Lead scrap undergoes two stages during the recycling process: physical separation and chemical separation (smelting and refining) (Wernick and Themelis, 1998). Typically, lead scrap comes from spent automobile and industrial lead-acid batteries (LAB). These spent LABs are drained of the electrolyte and crushed into smaller manageable pieces for further processing using hammer mill and grinding procedures, followed by washing and gravity separation in hydro-separators to isolate the lead-containing components and other materials. There are three streams: lead materials (about $60 \%$ lead, $15 \% \mathrm{PbO}_{2}$, and $12 \% \mathrm{PbSO}_{4}$ ), polypropylene scraps, and sulfuric acid (Wernick and Themelis, 1998). The lead materials usually come from grids and posts (lead alloy) and electrode paste (lead oxides and sulfides).

Smelting is the reduction of lead compounds to elemental lead in a high-temperature furnace which operates at higher temperatures $\left(2200^{\circ}\right.$ to $2300{ }^{\circ} \mathrm{F}$ or $1200^{\circ}$ to $1260{ }^{\circ} \mathrm{C}$ ) than those required for elemental lead $\left(621^{\circ} \mathrm{F}\right.$ or $\left.327^{\circ} \mathrm{C}\right)$. Depending on the smelter's practices and process, the recovered lead-containing materials are directly fed to the smelting furnace, or, first desulfurized then fed to the furnace (e.g., blast or electric furnace). The reduction of feed in the furnace yields raw lead product and slag rich (containing 20\% to 40\% lead) in lead content. The slag is fed back to the furnace for further reduction and lead recovery. The remaining slag is usually discarded as solid waste in landfills or sold to other industries as raw material (e.g., material in Portland cement). Following smelting, the recovered lead is transferred to refining kettles where lead is melted to remove the residual impurities to recover pure lead or to adjust other trace elements to produce alloys as per customer requirements and cast into ingots for shipment.

A simplified flow process diagram is shown in Fig. 1 for secondary lead smelting (USEPA, 1998). The lead recycling process consists of three stages, namely, pre-, in- and post-processing. The physical separation step constitutes the pre-processing stage. The chemical separation makes up the in-processing stage including the smelting and refining processing. It should be noted that the smelting stage consists of charging lead scrap to a reverberatory furnace. Consequently, the reverberatory furnace slag is used as feed material to blast or electric furnace for lead recovery. The third stage consists of postprocessing, that is, the application of pollution control technologies.

Fig. 2 presents four possible practices in US secondary lead smelting operations. In the first case, spent batteries are directly fed to the high temperature furnace. The second scenario separates the plastic components from the remainder of spent batteries in which lead scrap and battery paste are fed to the high temperature furnace. The third scenario is a variation of the second case where a drying/roasting unit is introduced between the battery breaking/ hydro-separation unit and the high temperature furnace. Lastly, the fourth scenario adds a desulfurization unit to the components in the third scenario for the significant reduction of, among other things, $\mathrm{SO}_{2}$.

\section{Methods}

\subsection{Search strategies}

Initially, the search concentrated on in-processing technologies in the US and abroad. However, in light of the application of inclusion criteria such as economic payback and efficiency, the evidence-based research team realized that the search should be extended to environmental technologies and practices at the pre-, in-, and postprocessing stages. In addition, we expanded the search to metal recovery at large, that is, it was not exclusive to lead processing. Thus, the redefined target areas in our search were: (a) current environmental practices and technologies adopted by US industries and abroad in the lead recycling process; (b) improved environmental practices and technologies for use in all stages of the lead recycling process; and (c) environmental practices and technologies applicable to pollution prevention and control technologies at the pre- and postprocessing stages in the metal recycling process at large. 


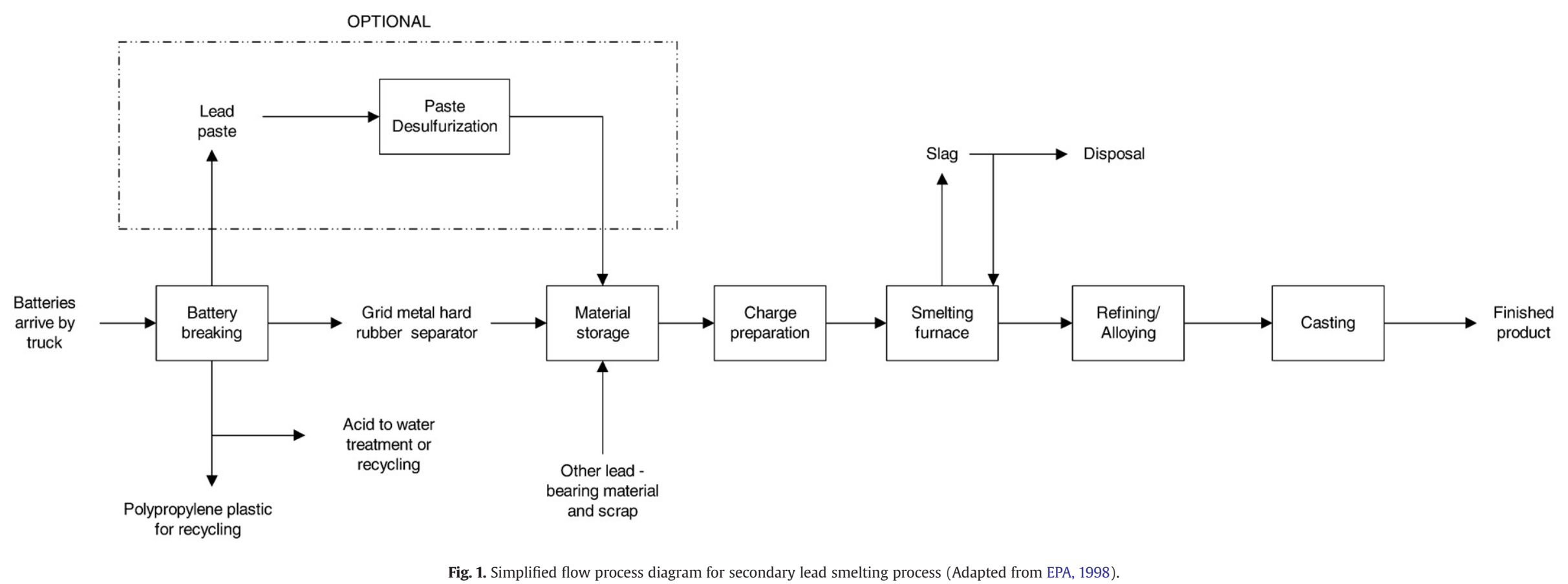


a

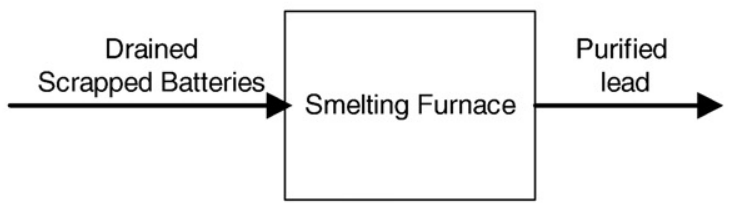

Polypropylene/Ebonite battery casing parts

b
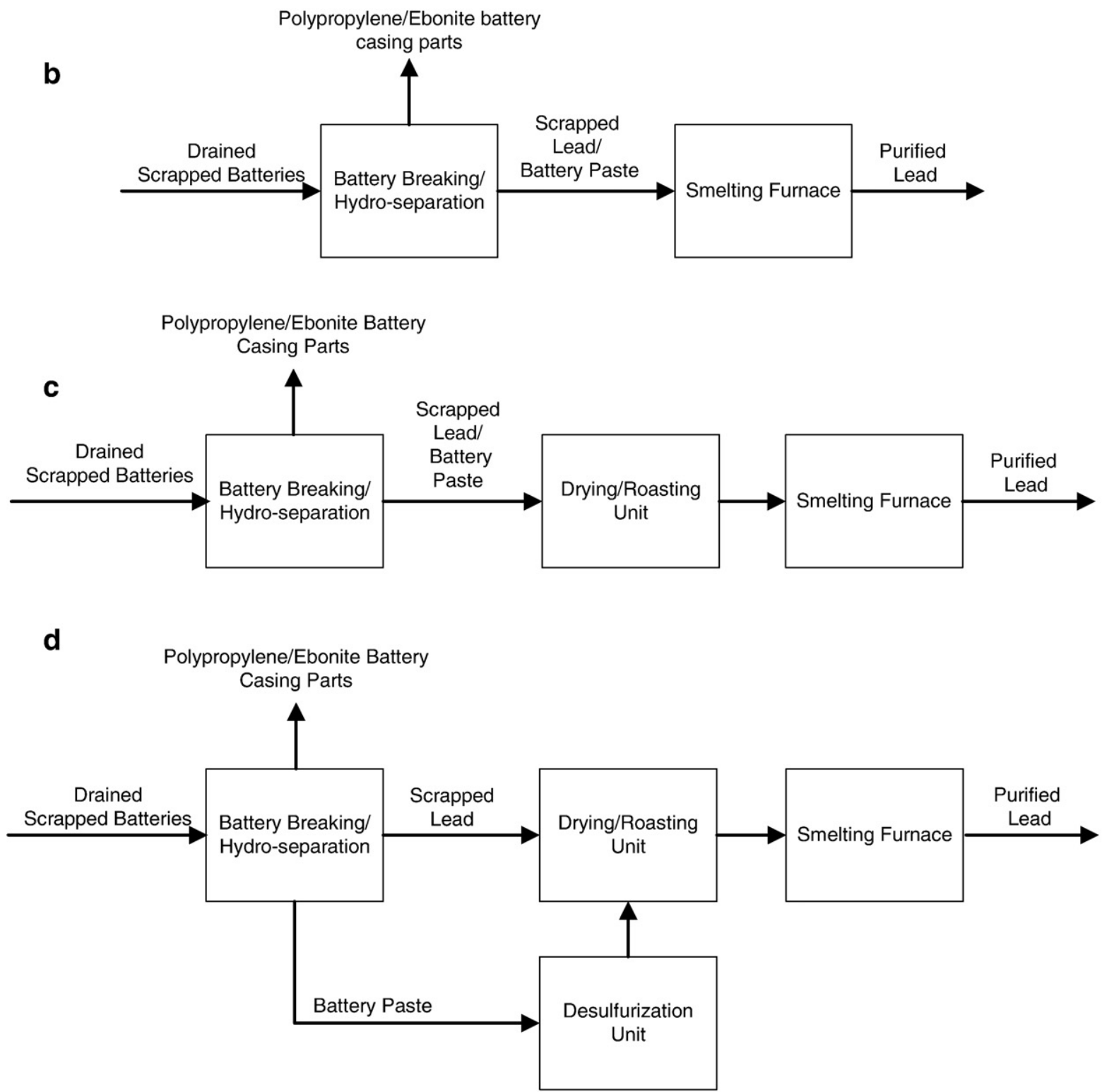

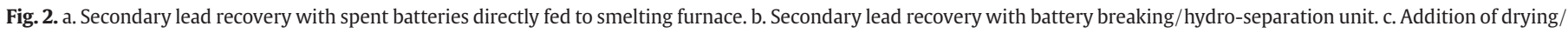
roasting unit to set-up in panel b. d. Addition of desulfurization unit to set-up in panel c.

The detail of comprehensive search of electronic databases is outlined below in support of the above target areas.

- For current in-processing practices and technologies in the US and abroad, we consulted the environmental databases of Academic Search Premier and Environetbase and general search engines such as Google and Yahoo with combinations of the following keywords: secondary lead smelting, smelting technologies, lead recycling technologies, and reclaiming and clean technologies. An emphasis was placed on articles emphasizing technologies in terms of efficiency and economic impact.

- For improved pollution prevention and control technologies relevant to all three stages of the smelting operation, specialized databases were used, namely, Academic Search Premier, Environetbase, Environment Complete and IEEE Electronic Library Online. General purpose search engines were also used including Google and Yahoo. The following combinations of keywords were used: pollution prevention technologies, air emission control technologies, gas emission control technologies, and waste water treatment technologies. Inclusion criteria included efficiency, economic payback, and energy expenditures/savings.

- The above databases were also searched for articles on practices and other technologies aiming at improving metal recovery at the pre- and post-processing stages. The following keywords and combinations were used: secondary lead smelting, best practices, 
pre-processing technologies, smelter feed, feed preparation, scrap separation, lead scrap treatment. In this light, individual and review articles were included.

\subsection{Data and information extraction for evidence description}

To accomplish Aims 2 and 3, the following items were documented for the evidence description of technologies and practices current and improved) for the three stages of secondary lead smelting: (a) Preprocessing - Technology description, efficiency (\%), cost-effectiveness (\% energy savings or expenditures per ton of metal recovered), payback period (years), environmental benefits (e.g., reduction in slag and $\mathrm{SO}_{2}$ ) and production increases (\% increase in throughput); (b) Inprocessing - Technology description, furnace efficiency (\%), costeffectiveness in terms of energy expenditures per ton of metal recovered (GJ/ton of lead), and effectiveness (purity of metal recovered in \%); and (c) Post-processing - efficiency (\%), cost-effectiveness in terms of energy expenditures per ton of metal recovered ( $\mathrm{GJ} /$ ton of lead), payback (yrs), and effectiveness in terms of concentration of contaminant in treated gas or water $\left(\mathrm{mg} / \mathrm{Nm}^{3}\right.$ for gas flow or $\mathrm{mg} / \mathrm{l}$ for processed water). Data and information were gathered for each type of technology/practice from one or more articles by one member of the research team and was verified by another member. Any discrepancies were resolved in consensus meetings.

\subsection{Assessment of economic/environmental cost and benefits for improvement options}

To achieve Specific Aim 4, the third scenario shown in Fig. 2c was utilized as the example to demonstrate the economic and environmental costs and benefits of adopting improved technologies and practices. A detailed account of the benefits and costs was presented with respect to changes in production, energy and material inputs, and environmental emissions. The analyses were made with reference to small (production capacity of 10,000 t), medium (i.e., 50,000 t) and large smelters (i.e., 100,000 t).

To achieve Aim 5, a methodology was devised to rank order the different options of bundles of improved environmental technologies and practices. In order to encourage the diffusion of improved technologies and practices, we assumed that the in-processing technologies in secondary smelting are not changing due to prohibitive costs of their replacement. Accordingly, our efforts concentrated on improvement of technologies and practices at the pre-processing stage. To assess the different options, an algorithm was developed which took into account the following criteria: (a) cost of capital investment and (b) benefits from production increases, energy and flux savings, and environmental emission reduction ( $\mathrm{SO}_{2}$ and slag). All benefit indices were estimated in monetary values and were converted into a percentage level relative to the predicted revenues for smelters depending on its size (10,000 $\mathrm{t}$ for small smelters; $40,000 \mathrm{t}$ for medium smelters; and 100,000 t for large smelters).

The overall benefit level was derived using the step-by-step process outlined in Fig. 3. In step 1, production increase is evaluated into one of four levels, namely, very low, low, moderate and high. Both energy/flux savings and environmental benefits are computed in units relative to production increase, that is, no change, increase by $1 /$ 2 level, or increase by one level as shown in steps 2 and 3 in Fig. 3, respectively; then, the energy/material savings and environmental benefits are converted into a single score by utilizing the conversion factor in step 4 (Fig. 3). Finally, the overall benefits are determined by integrating the values of production increase and energy savings/ environmental benefits (see step 5). For example, if the converter outcome is ' 1 level' and the level of production increase is 'high', the product will yield a 'very high' overall benefit. The one-time capital cost investment was converted into an annual basis by dividing the value by 4 years to be able to compare it on equal level with annual benefits (a 4-yr normalization value was selected because it corresponds to the payback period for hydro-metallurgical units as reported in Table A3 in Appendix A). Consequently, the obtained value was converted to a percentage level relative to the smelter's estimated revenues as explained above. The percentage value was transformed into a linguistic descriptor as shown in Fig. 3 (Step 6).

To illustrate the process of converting the numerical value into a linguistic descriptor for a benefit or cost variable, let us assume for example that a production increase in the improved blast furnace system for a small smelter is valued at $\$ 17 \mathrm{M}$. Relative to the smelter annual revenues (e.g., $\$ 27 \mathrm{M}$ ), this is equivalent to $62 \%$ of the annual revenues and equates to a 'High' level (see Fig. 3). It should be noted that one cannot easily translate the significant reduction in $\mathrm{SO}_{2}$ emission into monetary values. Therefore, given that the reduction in $\mathrm{SO}_{2}$ is comparable to that in slag reduction, the percentage value assigned to the reduction in slag was assumed to be the same as that for the reduction in $\mathrm{SO}_{2}$.

Fig. 3 depicts the compatibility function for integrating the costs and benefits into a single index ranging in values from 'Very Low', 'Low', 'Moderate', 'High' to 'Very High'. The compatibility function takes into account not only the payback period for the option at hand, but also, the economic and environmental benefits beyond the payback period. In a way, the compatibility function can be seen as a sustainability index integrating the economic, environmental and societal costs and benefits under one umbrella.

The assessment algorithm is used to calculate the compatibility function in several steps as follows: (1) Production increase is assigned a linguistic descriptor ranging from 'Very Low' to 'High' as shown in Step 1 of Fig. 3; (2) The energy and flux savings are evaluated as reported in Step 2 of Fig. 3 to determine the action required ranging from 'No Change' to 'Increase by $1 / 2$ Level' to 'Increase by One Level'; (3) Step 3 of Fig. 3 calls for a similar action in terms of the added environmental benefits of both $\mathrm{SO}_{2}$ and slag reduction; (4) The action outcomes from Steps 2 and 3 are added up to obtain an intermediate action for the integration of energy/flux savings and $\mathrm{SO}_{2} / \mathrm{slag}$ reduction ranging from 'No Change' to 'Increase by $11 / 2$ Level'; (5) The outcome of production increase obtained from Step 1 of Fig. 3 is modified by an integration of the intermediate action outcome from both the energy/flux savings and $\mathrm{SO}_{2}$ / slag reduction to arrive at the overall benefit level (step 5); (6) The overall cost is assigned one of five values ranging from 'Very Low' to 'Very High' as demonstrated in Step 6 of Fig. 3 ; (7) the compatibility function is calculated for a given value of cost and benefit using the table shown in Fig. 3 and is assigned a value ranging from 'Very Low' to 'Very High' (Step 7).

It should be noted that combining energy and flux savings together with environmental emission reduction may lead to improvement in the order of $1 / 2$ units (see footnote in Fig. 3). Thus, one may add a 'somewhat' level between two consecutive descriptors, for example, 'low' and 'moderate' becoming 'somewhat moderate'. Therefore, the benefit scale (i.e., in steps 1, 5 and 7) will consist of the following levels: 'Very Low', 'Somewhat Low'; 'Low', 'Somewhat Moderate', 'Moderate' 'Somewhat High', 'High', 'Somewhat Very High' and 'Very High' (please see a refined table of the compatibility function in the footnote of Fig. 3). The compatibility table was developed using a round table of experts in industrial management.

\subsection{Identification of studies}

\subsubsection{Smelting technologies}

The search of electronic databases for smelting technologies resulted in 1452 citations (Fig. 4a). Seventy-two abstracts were retrieved after removing repeated abstracts, review articles and abstracts not related to the topic. Upon application of inclusion criteria (e.g., efficiency, costeffectiveness, output purity), a total of 28 articles were fully examined and twenty-one studies were finally selected for use in our evidencebased methodology (Andrews et al., 2000; Baldock and Short, 2000; Cow-perthwaite et al., 1980; Diaz et al., 2001; Ferracin et al., 2002; Frias 
Overall Benefits

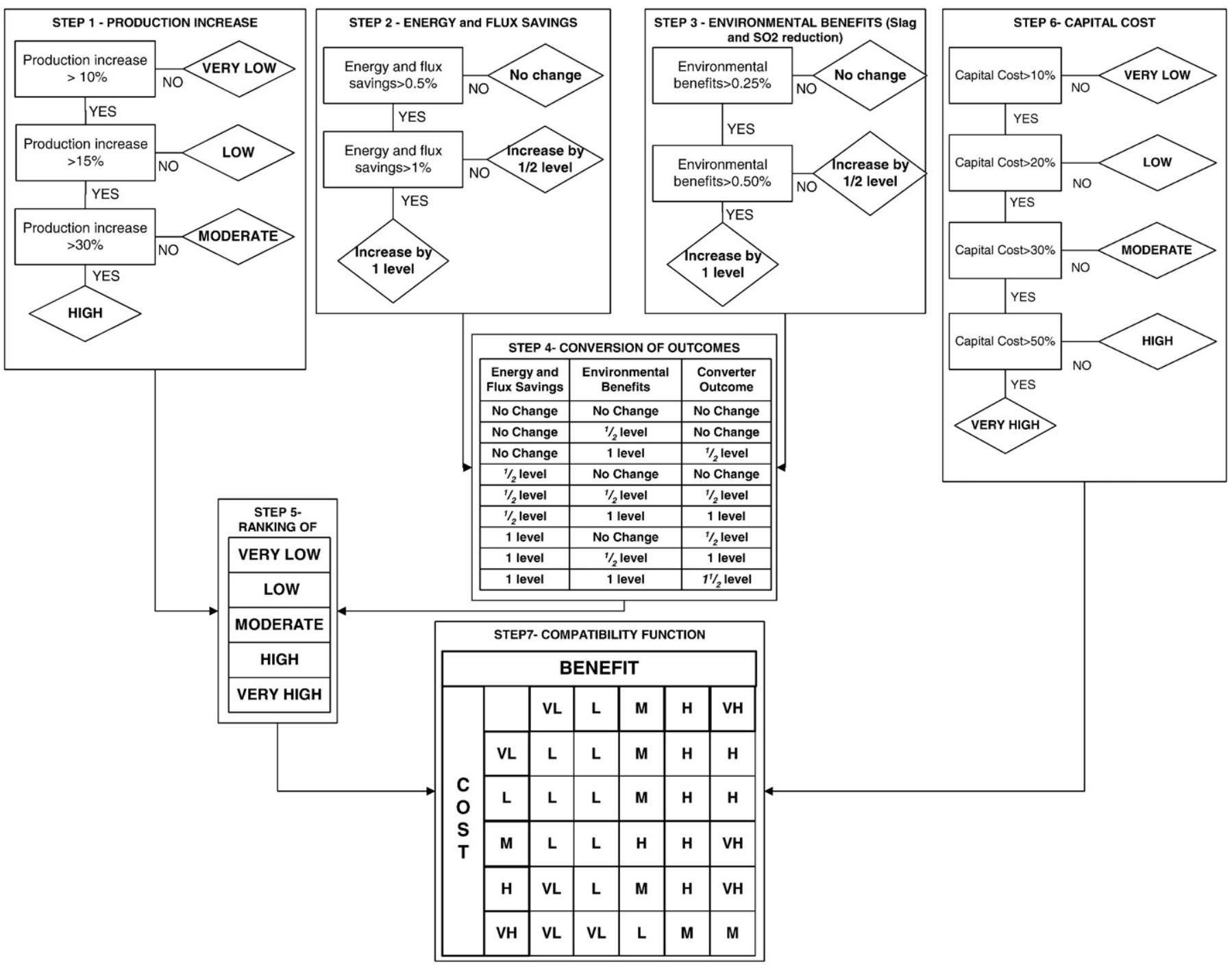

Fig. 3. Calculation of compatibility function. (VL - Very Low; L - Low; M - Moderate; H - High; VH - Very High).

Footnote:

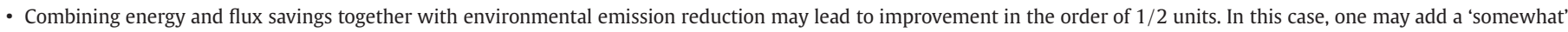
level between two consecutive descriptors such as low and moderate becoming 'somewhat moderate'. Therefore, the benefit scale (i.e., Steps 1,5 and 7 ) will consist of the following levels: VL - Very Low; SL - Somewhat low; L - Low; SM - Somewhat moderate; M - Moderate; SH - Somewhat high; H - High; SVH - Somewhat very high; VH - Very High.

- The final compatibility matrix is shown below while incorporating the 'somewhat' levels:

\begin{tabular}{|c|c|c|c|c|c|c|c|c|c|c|}
\hline \multirow[t]{7}{*}{ Cost } & \multicolumn{10}{|c|}{ Benefit } \\
\hline & & VL & SL & $\mathrm{L}$ & SM & $\mathrm{M}$ & $\mathrm{SH}$ & $\mathrm{H}$ & SVH & $\overline{\mathrm{VH}}$ \\
\hline & $\overline{\mathrm{VL}}$ & $\mathrm{L}$ & $\mathrm{L}$ & $\mathrm{L}$ & SM & $\mathrm{M}$ & $\mathrm{SH}$ & $\mathrm{H}$ & $\mathrm{H}$ & $\mathrm{H}$ \\
\hline & $\mathrm{L}$ & $\mathrm{L}$ & $\mathrm{L}$ & $\mathrm{L}$ & SM & M & $\mathrm{SH}$ & $\mathrm{H}$ & $\mathrm{H}$ & $\mathrm{H}$ \\
\hline & M & $\mathrm{L}$ & $\mathrm{L}$ & $\mathrm{L}$ & $\mathrm{SH}$ & $\mathrm{H}$ & $\mathrm{SH}$ & $\mathrm{H}$ & SVH & VH \\
\hline & $\mathrm{H}$ & VL & $\mathrm{L}$ & $\mathrm{L}$ & SM & M & $\mathrm{SH}$ & $\mathrm{H}$ & SVH & VH \\
\hline & VH & VL & VL & VL & SL & $\mathrm{L}$ & SM & M & $\mathrm{M}$ & M \\
\hline
\end{tabular}

et al., 2002; Agrawal et al., 2004; Rabah, 1998; Ramus and Hawkins, 1993; Reddy, 2003; Raghavan et al., 2000; Tianjun and Qichang, 1999; Errington et al., 2005; Arthur and Edwards, 2003; Zhang et al., 2008; Ziebik and Stanek, 2006; Barakat, 1998; Ettler et al., 2005; Ryzhenkov et al., 2006; Socolow and Thomas, 1997; Yender, 1998).

\subsubsection{Pollution prevention and control technologies}

The electronic search for pollution prevention and control technologies applicable to secondary lead smelting produced 1784 citations of which 1556 articles were eliminated on the basis of irrelevance to the study objective (Fig. 4b). After elimination of review and repeated articles from different databases, fifty-eight articles were short listed and read. Upon screening with respect to technology characteristics (e.g., efficiency), thirteen research papers were deemed appropriate for our study (Freeman et al., 1992; Hilson, 2000; Warhurst and Bridge, 1996; Hilson, 2003; Matheickal and Yu, 1997; De-Bruijn et al., 1996; Jaworek et al., 2006; Mooiman et al., 2005; Moss, 2008; Kreusch et al., 2007; Jolly and Rhin, 1994; Hossain 
a

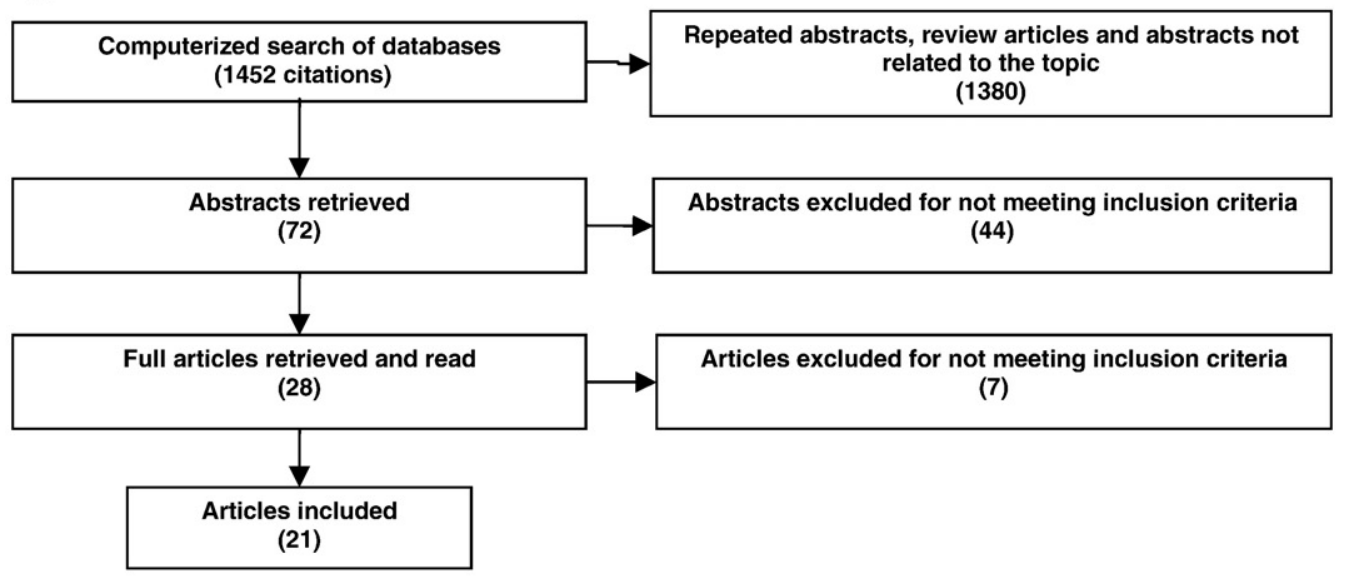

b

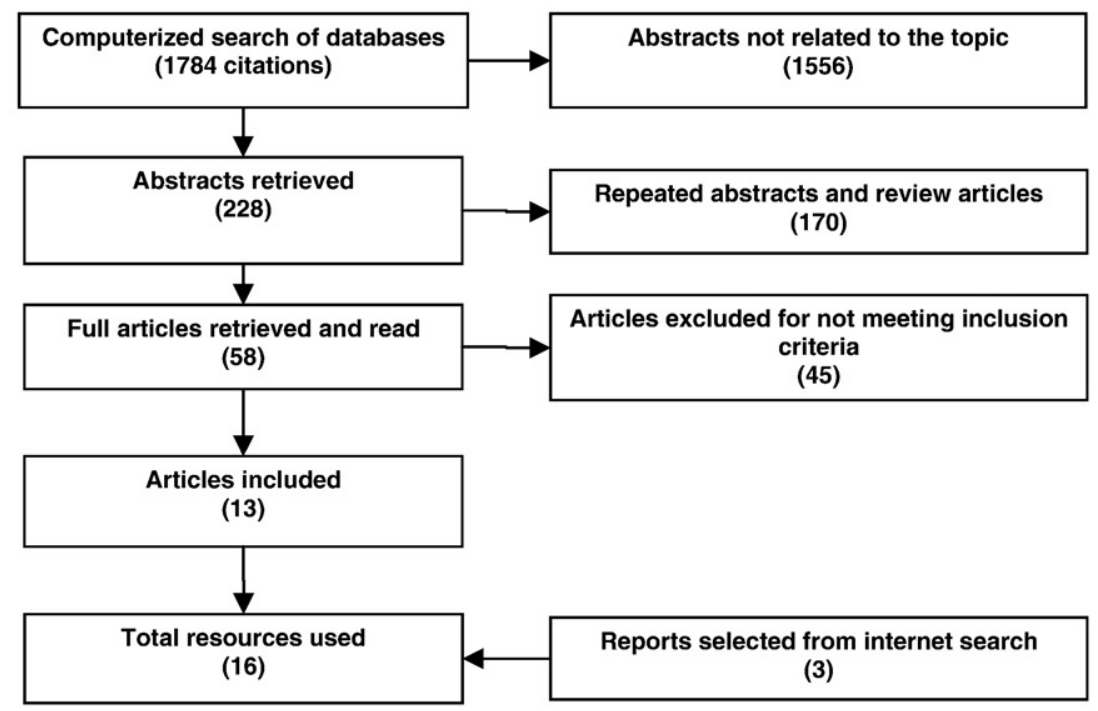

C

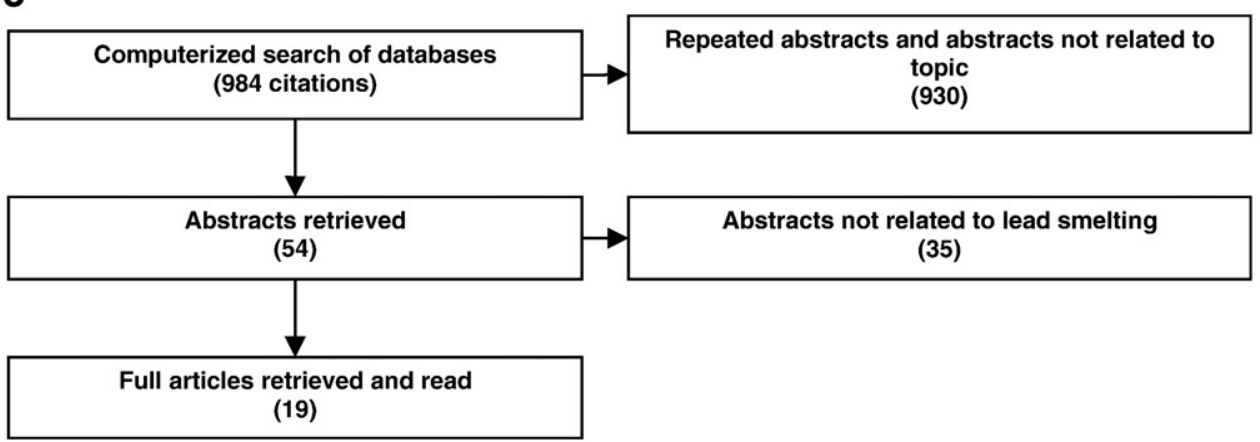

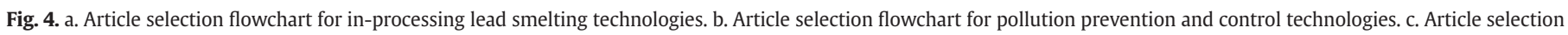
flowchart for additional technologies and practices for metal recovery.

et al., 2008; El-Halwagi 1998). Three additional reports were identified and found of use in the present study in light of internet inquiry on general purpose search engines (UNEP, 2003; USEPA, 1998; European Commission - Integrated Pollution Prevention and Control, 2001).

\subsubsection{Additional practices and technologies}

Fig. 4c provides a summary of the article selection search procedure for additional technologies and practices designed to max- imize metal recovery at the pre- and post-processing stages during the recycling process. A total of 984 citations were found. Fifty-four abstracts were selected after eliminating repeated abstracts and papers which are not relevant to the study objective. The following nineteen articles were finally used to support the study specific aims (Kang and Schoenung, 2005; Scott et al., 1997; Mesina et al., 2007; van Schaik and Reuter, 2004; Salomone et al., 2005; Vaysgant et al., 1995; Rabah, 1998; Quirijnen, 1999; Nakada et al., 2008; Lewis and 
Beautement, 2002; Kinaev et al., 2005; Driussi and Jansz, 2006; De Angelis et al., 2002; Dahodwalla and Heart, 2000; Espinosa et al., 2004; Coya et al., 2000; Bunge et al., 1996; Bourson, 1995; Zhao et al., 2008; Zabaniotou et al., 1999).

Upon completion of the primary electronic search and evidencebased analyses, the research team conducted another secondary search to fill in gaps found in the tables of evidence-based information discussed in the results section and reported in the Appendices. Additional studies and reports include, among others, the work of Akihiko (2004), Abrams et al. (1999), Hughes (2000), Kenson (2005), Lyakov et al. (2007), Olson (2008), Olympia Resource Limited (2005), Saman and Nutter (1994), Warner et al. (2006), Wolters et al. (2008), and Xstrata (2006).

\section{Results}

\subsection{Description of evidence}

The description of evidence is documented in Appendix A. Tables A1 through A4 provide the description and characteristics of in-processing technologies in typical US secondary smelting plants, improved in-processing technologies (not currently used in US plants), and pre- and post-processing technologies, respectively. The sources of emissions and pollutants during the smelting operations are outlined in Fig. 5a for typical activities conducted in US recycling plants based on pyro-metallurgical techniques. Fig. 5b documents the emissions for improved hydro-metallurgical technologies.

\subsubsection{Current technologies and practices used by US smelters}

The US lead smelting industry uses reverberatory, blast, rotary and electric furnaces for smelting lead scrap to produce refined lead. As a first step, the batteries are broken down by hammer mills or sawing and scrapped lead is separated via hydro-separation. Few of the smelters use desulfurization units to remove sulfur from lead prior to being fed into high temperature furnaces. The recovered lead scrap is dried and mixed with other lead-content materials. Measured quantities of feed are processed with flux and reducing agents in high temperature furnaces, usually reverberatory, to separate elemental lead from other impurities. Soft lead is tapped from the furnace and the generated slag rich in lead content is further reduced in blast or electric furnaces. Thereafter, soft lead is purified or alloyed in kettles and cast to lead billets per customer requirements.

The emissions in the secondary lead smelting process are controlled to meet environmental regulations. Baghouse filters are used to collect the dust produced during battery breaking, drying and feed preparation and smelting. Some smelters process the battery paste directly into the high temperature furnaces, therefore, the plants are equipped with gas scrubbing units to remove the sulfur dioxide produced during the process in the form of sulfuric acid. Other emissions such as carbon monoxide and dioxide, and dioxins are burned with the dust collected in bag filters. Lead dust collected in bag filters is redirected to the furnace for further smelting.

Vast amounts of water are used at different points in secondary lead smelting operations including hydro-separation units, furnace cooling, quenching, and emission control equipment. The resulting contaminated water with lead and lead compounds and other acids and alkalies is collected and treated in tanks and reservoirs to remove contaminants. The treated water is reused in the smelter processes or released into the streams depending on the smelter practices and waste water.

\subsubsection{Improved technologies and practices}

Improved in-process smelting technologies include both pyro- and hydro-metallurgical processes (UNEP, 2003). Pyro-metallurgical tech- niques reduce all metallic compounds via chemical methods to their metallic or reduced forms by means of heating and use of fluxing and reducing agents. Prior to smelting, some pyrometallurgical techniques employ desulfurization and neutralization steps. Following smelting, a refining step is required in which specific reagents are added to molten lead at appropriate temperatures. The reagents will remove the unwanted metals.

Hydro-metallurgical technologies reduce all lead compounds to metallic lead electrically via electrolysis that deposits lead on electrodes, which is subsequently shaken off, collected and pressed to form platelets of pure lead. A comparative assessment of hydro- and pyro-metallurgical techniques reveals the following observations:

- Hydro-metallurgical methods are highly effective in producing pure metals. Its efficiency is comparatively higher than that of pyrometallurgical procedures.

- Hydro-metallurgical processes can be altered to accept a wide range of feed materials with minimally invasive process changes.

- The production output capacity of pyro-metallurgical technologies is much higher than that of hydro-metallurgical processes.

- The points of emissions are significantly less in hydro-metallurgical methods (Fig. 4b) in comparison to pyro-metallurgical process (Fig. 5a).

It should be noted that hydro-metallurgical units are produced in various sizes. In this research, smaller hydro-metallurgical units, as shown in a later section, are also presented as viable options in the pre-processing technologies to augment the capabilities of inprocessing technologies among US smelters (e.g. pyro-metallurgical units).

In addition to hydro- and pyro-metallurgical techniques, the following observations can be made about pollution prevention and waste minimization technologies and practices which can assist in reducing the sources of emissions during pre- and in- processing activities:

- Baghouse filters with fabric and ceramic filters are best suited for dust abatement with efficiency greater than $99.9 \%^{+}$.

- Significant reduction in hazardous gas emissions can be achieved through in- and post-processing after gas burners.

- End-of-pipe control technologies, such as sedimentation, can be used to capture material lost in water and dust during transportation, handling, processing and extraction of lead.

- The recycle and reuse of process/waste/treatment of water has significant economic impact.

- The desulfurization of battery paste prior to in-process smelting significantly reduces the amount of generated slag due to reduction/elimination of iron and savings in coke consumption. The efficiency of smelting operation can increase by 25 to $30 \%$ due to the desulfurization activity.

- Battery separation and smelting practices have a significant impact on slag reduction relative to smelting whole batteries (i.e., the whole battery is fed to high temperature furnaces).

- Prior to entry into the smelting phase, drying feed materials can significantly reduce the energy requirements of the furnace.

- The pre-sorting of batteries and lead-containing materials increases the furnace efficiency via increased throughput, and reduced emissions and generated slag.

\subsection{Example of economic/environmental costs and benefits for improved technologies and practices}

Appendix B documents the details of costs and benefits of introducing hydro-metallurgical techniques to the third scenario shown in Fig. 2c so as to improve the environmental practices of US smelters. The details are demonstrated for small, medium and large smelters. 


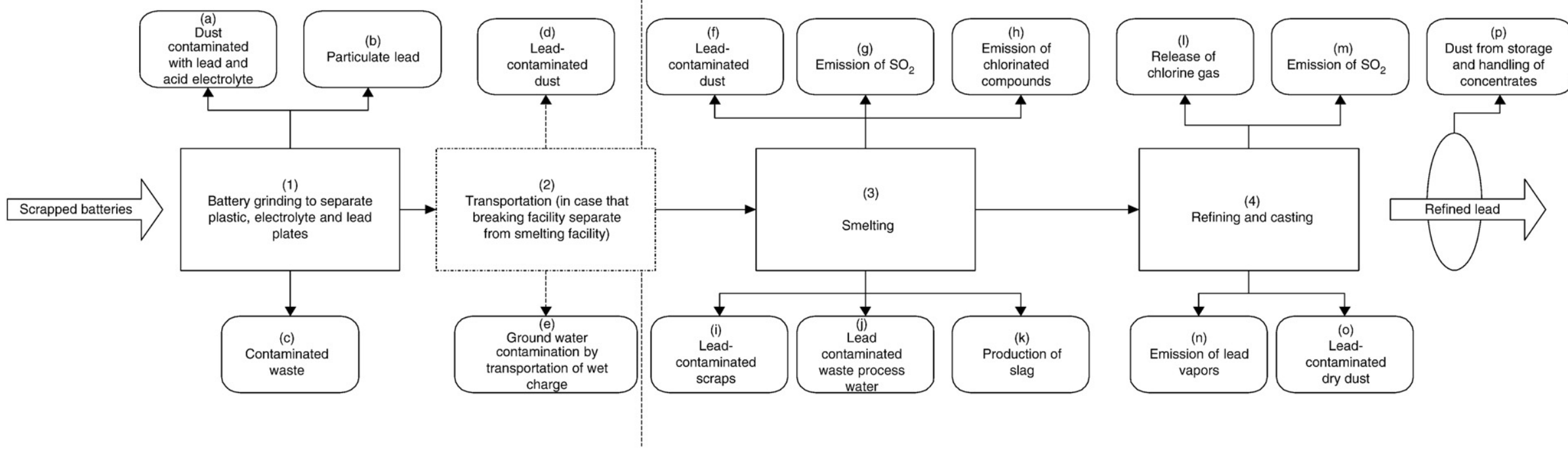

Fig. 5. a. Sources of emissions in pyro-metallurgical process.

Footnote:

1. Grinding of battery to separate plastic, electrolyte and lead plates:

- Dust contaminated with lead and acid electrolyte

- Particulate lead

- Contaminated waste

2. Transportation (in the event that a breaking facility is separate from a smelting facility):

- Dust contaminated with lead particulate and lead compounds

- Ground water contamination by transportation of wet charge

3. Lead reduction in a rotary furnace:

- Lead-contaminated scrap

- Lead-contaminated dust (from filters)

- Emission of $\mathrm{SO}_{2}$

- Emission of chlorinated compounds

- Production of slag

4. Separation of metallic lead from slag and refining:

- Emission of lead vapors

- Emission of $\mathrm{SO}_{2}$

- Production and removal of fine, dry dust with high percentage of lead and other metals

- Release of chlorine gas $\left(\mathrm{Cl}_{2}\right)$

5. Other sources:

- Dust from storage and handling of concentrates; Leakage from roasters and smelters; Miscellaneous ( $0.7 \mathrm{t} /$ year) 
b

Physical Separation

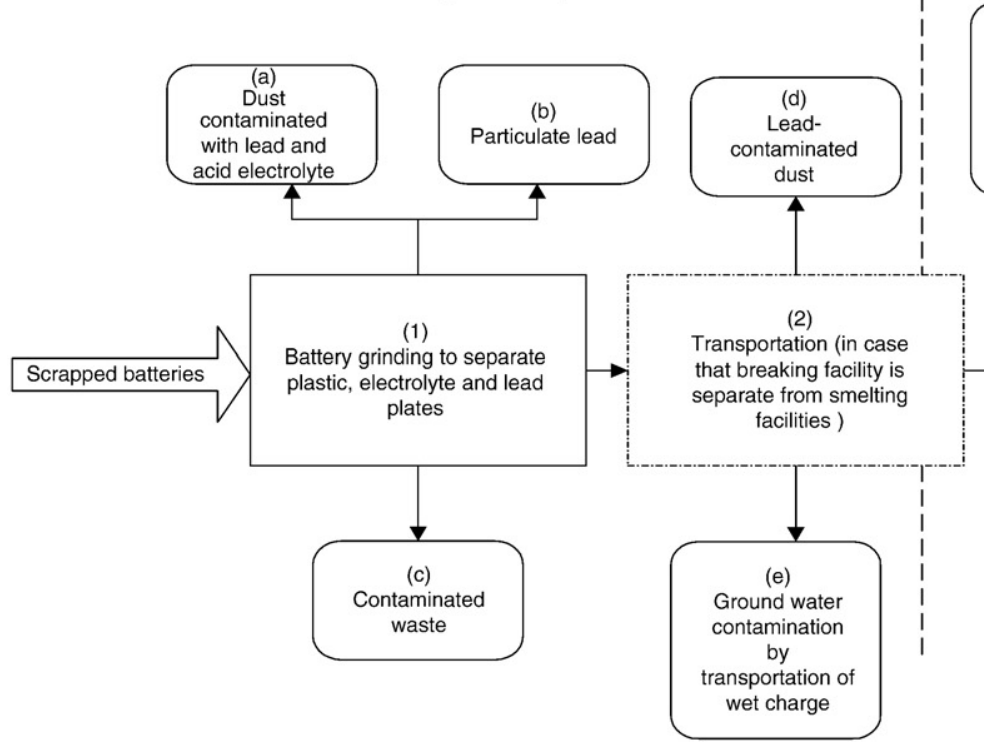

Chemical Separation

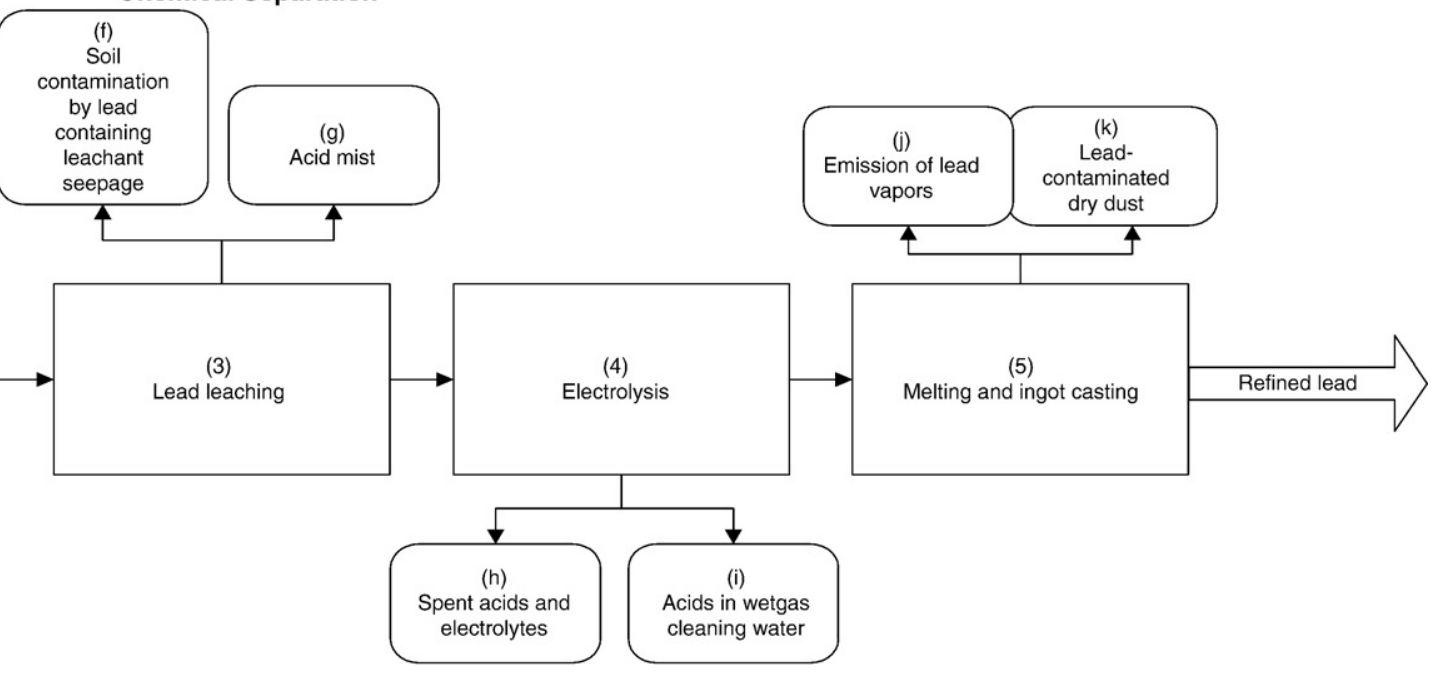

Fig 5. b. Sources of emissions in hydro-metallurgical process.

Footnote:

1. Grinding of battery to separate plastic, electrolyte and lead plates:

- Dust contaminated with lead and acid electrolyte

- Particulate lead

- Contaminated waste

2. Transportation (in the event that a breaking facility is separate from extraction facility):

- Dust contaminated with lead particulate and lead compounds

- Ground water contamination by transportation of wet charge

3. Lead leaching:

- Lead containing leachant seepage and contamination of soil in in-situ or dump leaching

- Dust contaminated with lead while transporting pregnant solution

- Acid mists (pressure leaching)

4. Electrolysis:

- Spent acids and electrolytes

- Acids in water from wet gas cleaning 
a

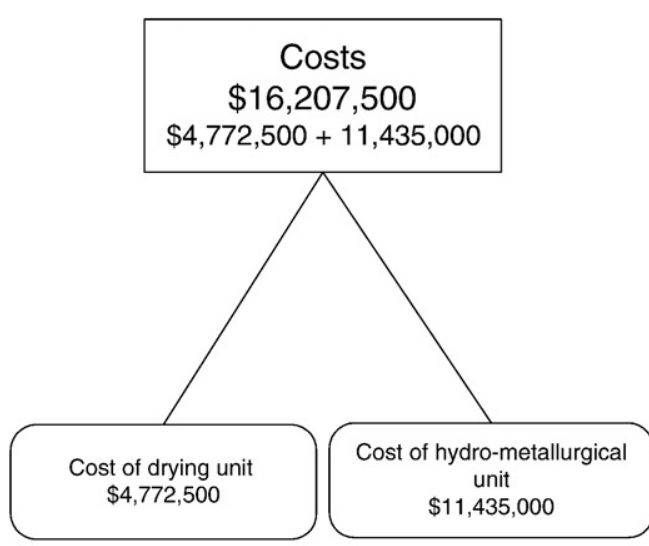

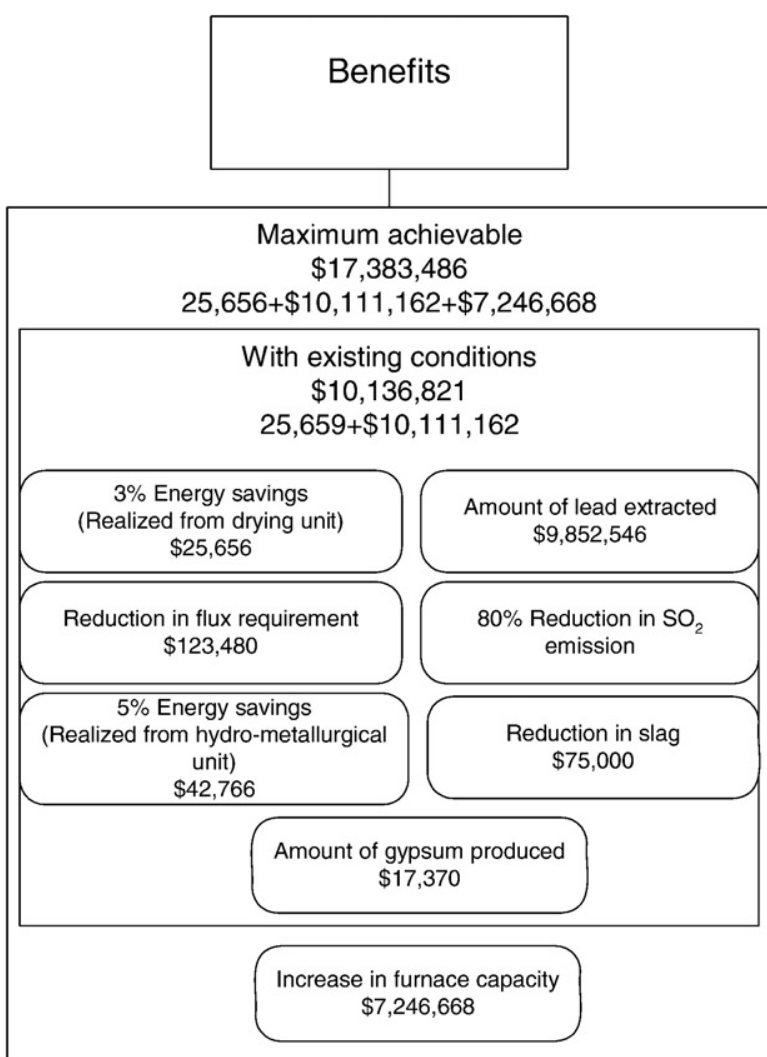

b
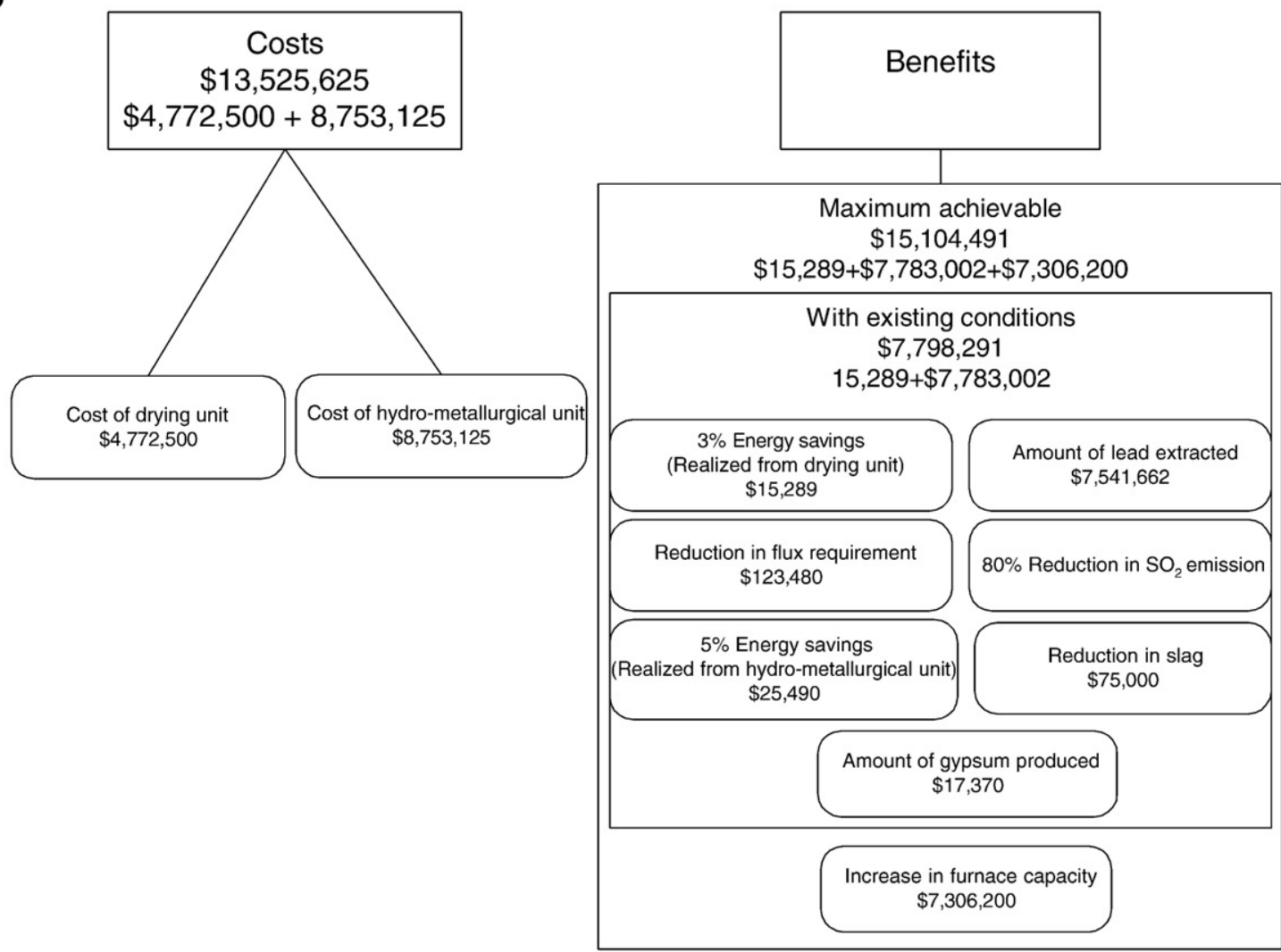

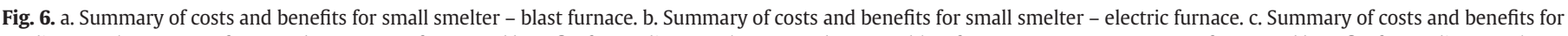

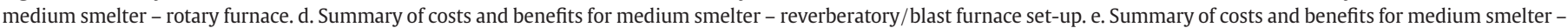

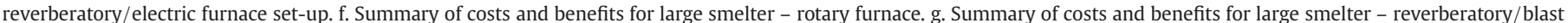
furnace set-up. h. Summary of costs and benefits for large smelter - reverberatory/electric furnace set-up. 
c
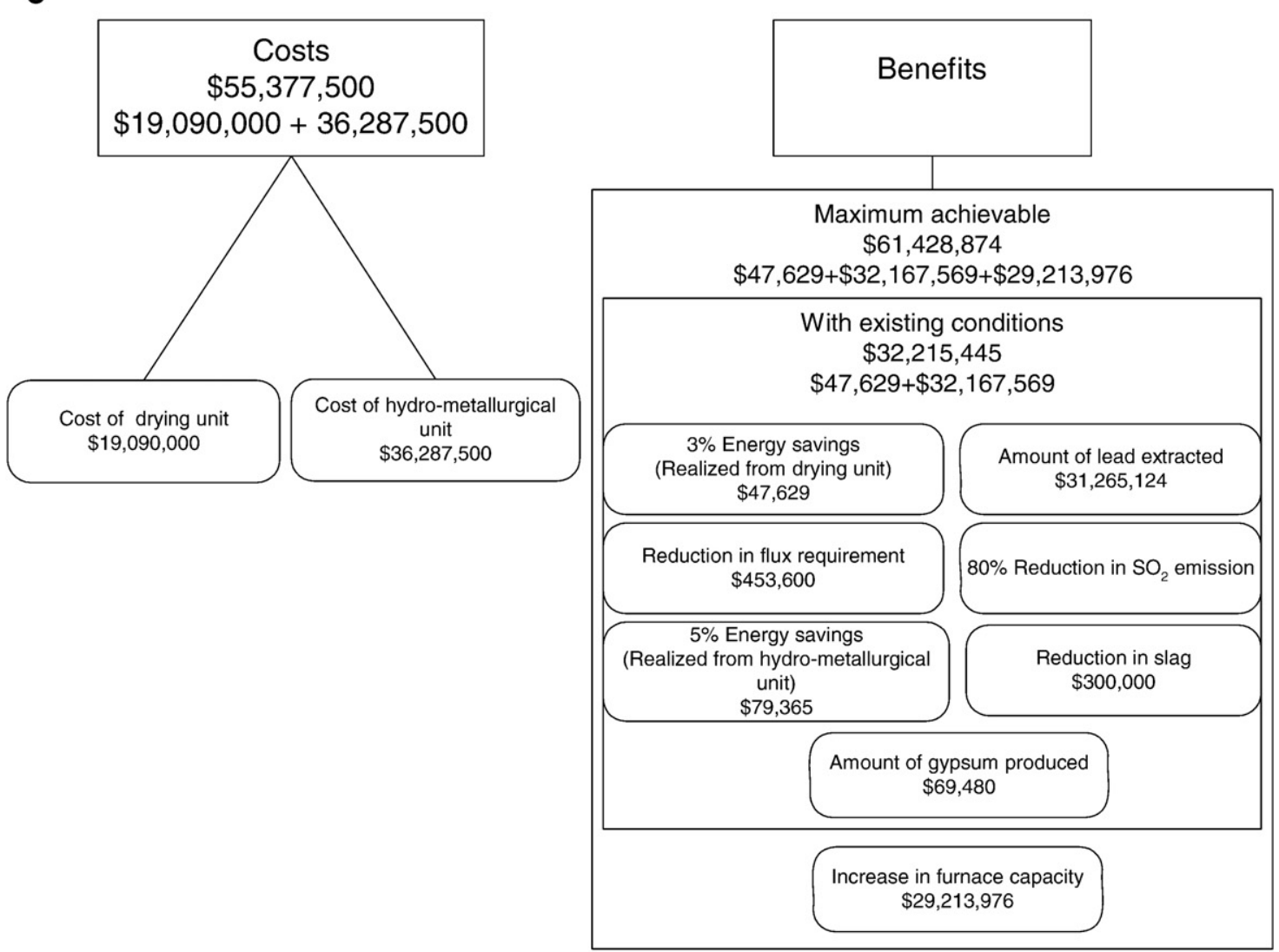

d

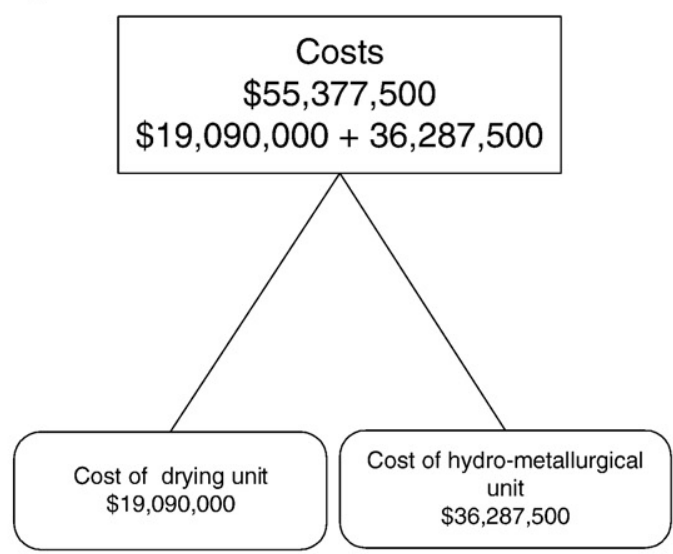

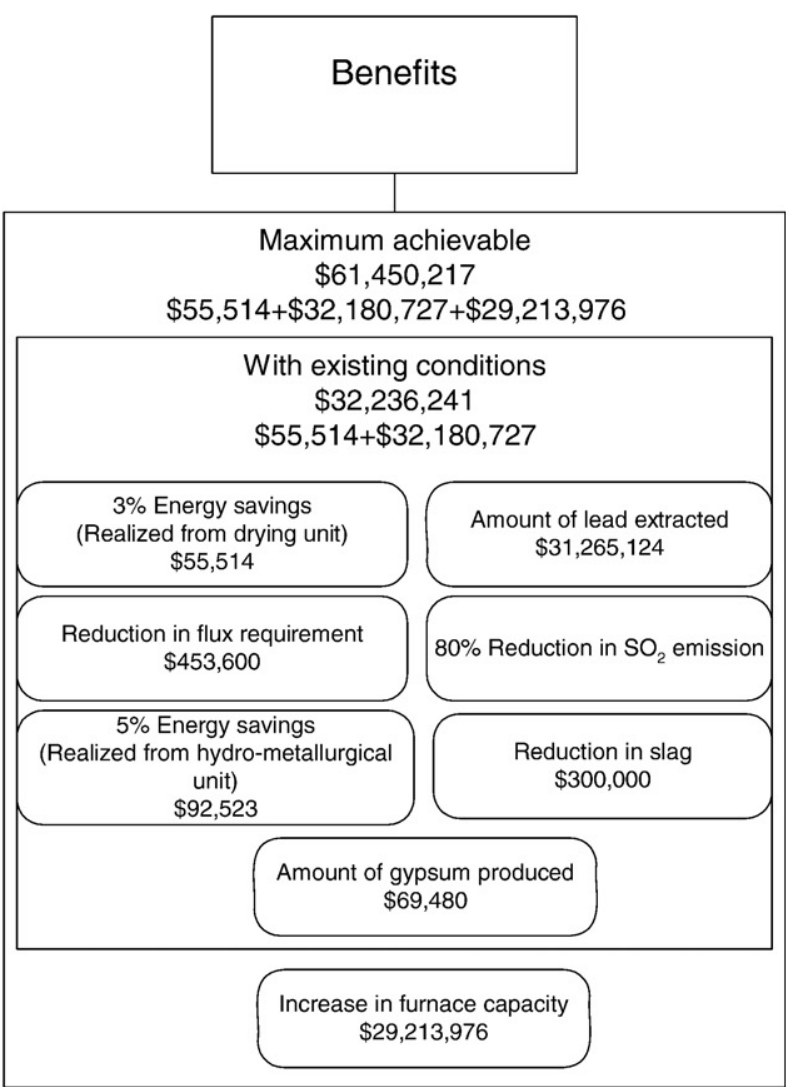

Fig. 6 (continued). 

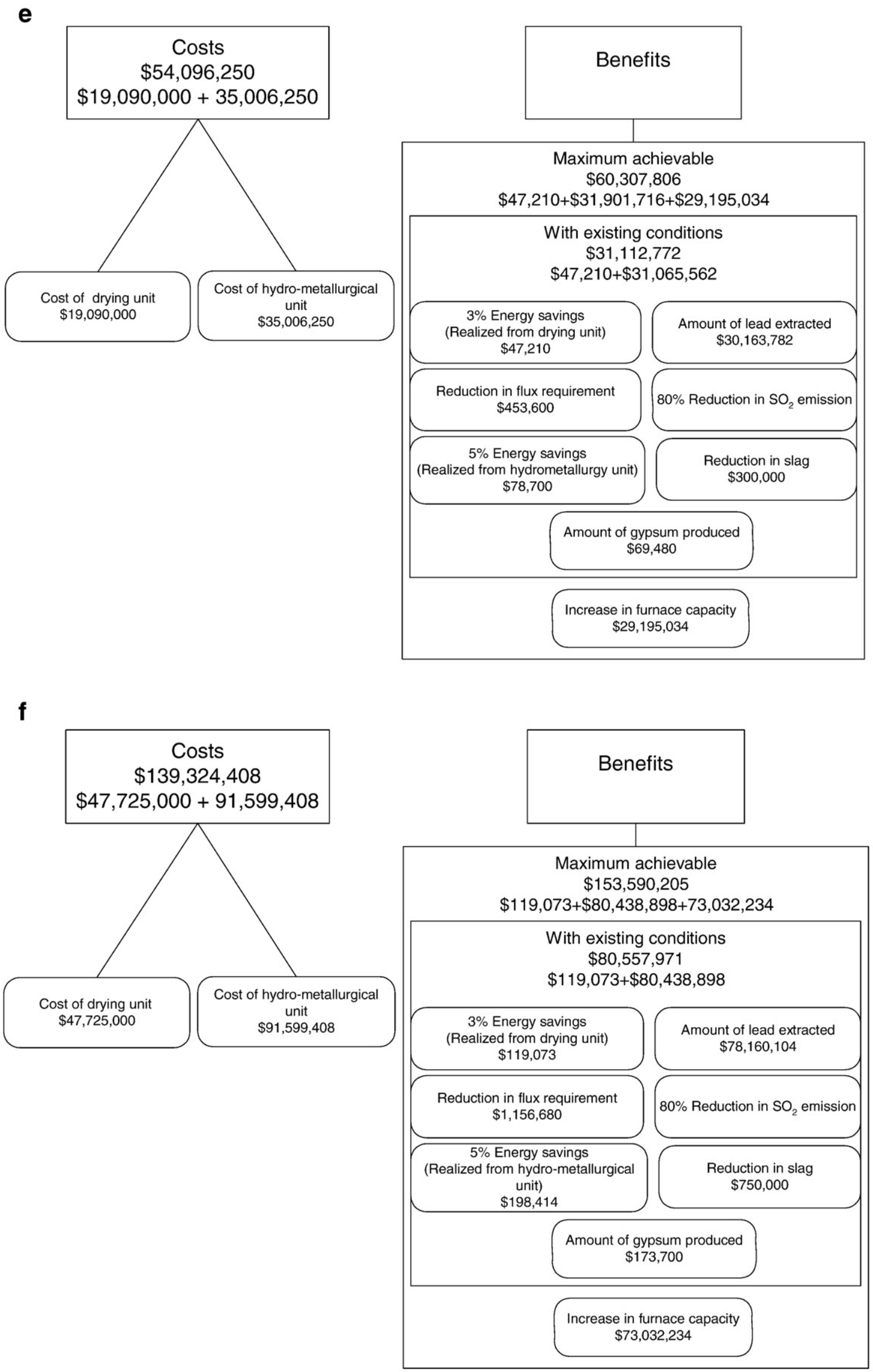

Fig. 6 (continued). 

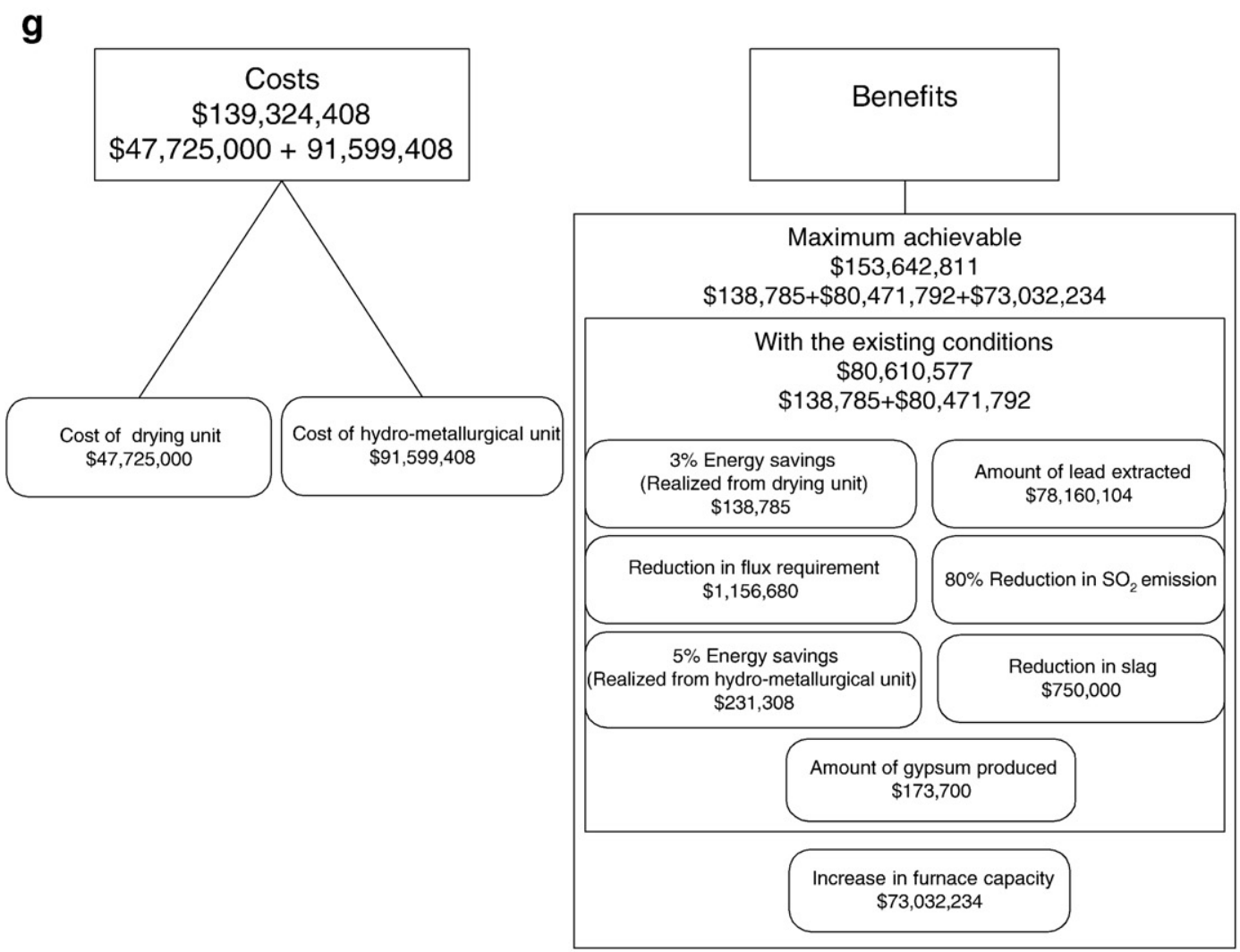

$\mathbf{h}$
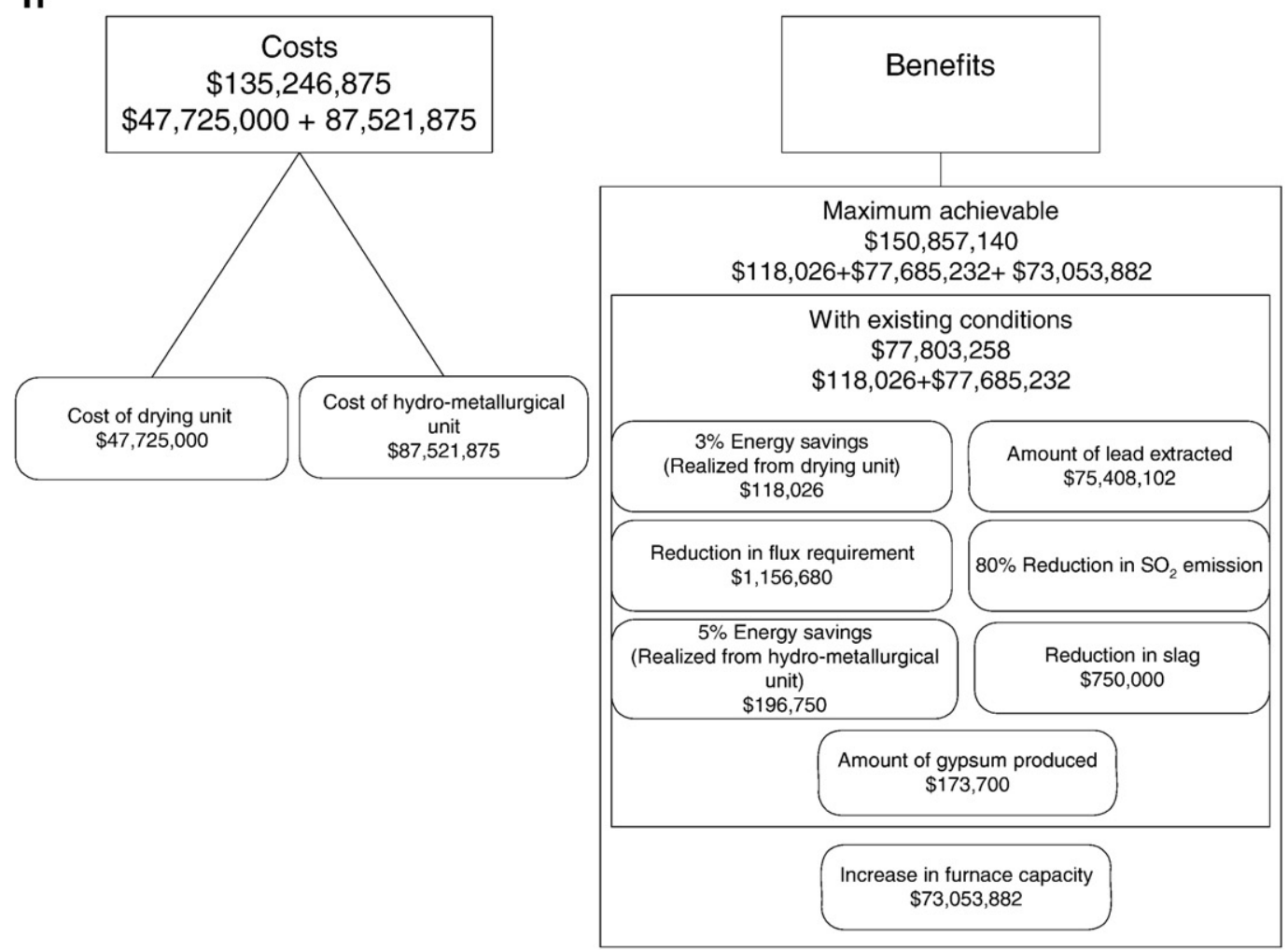

Fig. 6 (continued).

It was assumed that existing in-processing smelting technologies are kept as is for economic reasons. With this in mind, the costs and benefits are outlined for both blast and electric furnaces (small smelters with a capacity of 10,000 t), and rotary, reverberatory/blast and reverberatory/electric furnaces (medium and large smelters with capacities of 40,000 and $100,000 \mathrm{t}$, respectively). 
Fig. 6 shows a summary of the costs and benefits of the drying/ roasting and hydro-metallurgical units for different types and combinations of in-processing smelting technologies. The costs represent the one-time capital investment in improved technologies and practices. On the other hand, the benefits are presented on an annual basis for: (a) increases in refined lead production and creation of gypsum as secondary products accrued only via the hydro-metallurgical unit; (b) energy savings from both units; and (c) reduction in flux usage due to re-routing of battery paste directly to the hydrometallurgical unit as well as significant reduction in environmental emissions as evidenced by $\mathrm{SO}_{2}$ and slag removal. For small smelters, the benefits are higher for existing blast furnace set-ups because their efficiency is lower (91\%) than that of electric furnaces (99\%). Therefore, the full benefits of the hydro-metallurgical unit are realized for the blast furnace. Comparable benefits are achieved for different combinations of high temperature furnaces for medium and large smelters because of the comparable efficiencies of existing furnace set-ups.

\subsection{Options for integrated environmental solutions for secondary lead smelters}

Appendix $C$ provides an analysis of the different options in terms of costs and benefits for pre-processing technologies and practices. There are three pre-processing technologies and practices which can be adopted by US secondary lead smelters without significant changes. These include: (a) drying feed material prior to entry into high temperature furnace, (b) desulfurization of battery paste and slag, and (c) hydro-metallurgical processing of battery paste and slag. Air- and hydro-separation are the choices for physical separation or presorting lead scrap. The selection of presorting methods is dependent on the smelter's acceptance of its raw materials. The processing of a mix of leadcontaining materials (e.g. printed circuit boards in addition to LAB) can benefit from air separation units for feed enrichment. Finally, pollution control technologies for air emissions and waste water treatments are mature methods and there is a wide selection to choose from.

Table 1 provides a comparative assessment of different bundles of pre-processing pollution prevention technologies used to improve the performance of existing in-processing smelting technologies. The following observations can be made from this table.

- A drying unit is almost required in any bundle because it significantly reduces the energy requirements of high temperature furnace via removal of moisture and pre-heating the furnace charge.

- When added to an existing pyro-metallurgical smelting operation, a hydro-metallurgical unit significantly increases the metal recovery efficiency by extracting the metal content lost in slag and sludge generated from other pollution control devices.

- Although the rate of reduction in environmental air emissions, particularly $\mathrm{SO}_{2}$, is almost the same for both hydro-metallurgical and desulfurization methods, hydro-metallurgical methods use less energy than desulfurization units. In essence, pyro-metallurgical techniques require further processing of desulfurized paste, hence, higher energy requirements.

- The reduction in slag generated through the use of desulfurization or hydro-metallurgical units is attributed to the reduction in flux required to extract pure lead from sulfurized lead.

In light of the above, it appears that a bundle consisting of dried and hydro-metallurgical units considerably enhance the performance of existing pyro-metallurgical-based smelting plants from the standpoint of production, energy/material savings, and environmental emission reduction. Plants with added desulfurized units (see Fig. 2d) will achieve very high performance by adding the hydro-metallurgical unit. For small smelters, this option will close the gaps between blast and electric furnaces. For medium to large smelters, this option provides the best performance to a rotary furnace or a combination of reverberatory and electric/blast furnaces.

\section{Discussion}

In recent years, sustainable industries determined that conventional end-of-pipe environmental systems are not effective at damage remediation and are costly to operate and maintain (Hilson, 2000). It was concluded that the solution to these problems is to replace the conventional end-of-pipe equipment with cleaner technologies (i.e. equipment that emits little or no hazardous material or that tackles pollution at the source rather than after it is discharged) and to implement cleaner production practices as part of daily business operations. With the above in mind, the research reported herein deals with lead which makes up the largest hazardous waste in the U.S. and still presents a significant source of pollutants (Gearhart et al., 2003). In light of recent declining rates for metal recovery in the LAB product lifecycle in the US market (Genaidy et al., 2008), the focus of this study was to identify integrated environmental strategies to increase lead recycling, process efficiency and recovery in order to improve human and environmental health as well as the bottom line of secondary lead smelters, LAB and other lead product industries.

Typically, a secondary smelting operation consists of three stages: pre-, in- and post-processing. The in-processing stage is at the core of the smelting operation. From a smelter perspective, we assumed that one cannot replace the in-processing equipment given the high capital investment. Therefore, we concentrated our efforts on improving the operation at the pre-processing stage. An evidence-based methodology was deployed through a systematic review and appraisal of the scientific literature with an emphasis on solutions that can lead to recovery and recycling of the largest quantities of lead currently being disposed of as waste subject to technical and economic viability and strong industry interest. A comprehensive search of electronic databases and general purpose search engines was conducted to retrieve relevant articles and reports to the present research. The required data and information was extracted for the purpose of improving the operation of secondary lead smelters. Following data search and

Table 1

Summary of implementation priorities of suggested bundles.

\begin{tabular}{|c|c|c|c|c|}
\hline \multirow[t]{2}{*}{ Furnace type } & \multicolumn{4}{|c|}{ Pre-processing improvement practices } \\
\hline & Drying unit only & $\begin{array}{l}\text { Drying }+ \text { desulfurization } \\
\text { units }\end{array}$ & $\begin{array}{l}\text { Drying + hydro-metallurgical } \\
\text { units }\end{array}$ & $\begin{array}{l}\text { Drying }+ \text { desulfurization }+ \\
\text { hydro-metallurgical units }\end{array}$ \\
\hline Blast (small smelters) & Low & Somewhat Moderate & Very High & Very High \\
\hline Electric (small) & Low & Somewhat Moderate & High & Somewhat Very High \\
\hline Rotary medium to large) & Low & Somewhat Moderate & High & Somewhat Very High \\
\hline Reverberatory + blast (medium to large) & Low & Somewhat Moderate & High & Somewhat Very High \\
\hline Reverberatory + electric (medium to large) & Low & Somewhat Moderate & High & Somewhat Very high \\
\hline
\end{tabular}

Appendix $C$ shows the details of rank ordering of different bundles of environmental improvement technologies. 
extraction, the description of evidence was presented for current practices and technologies used by US smelters as well as improved practices and technologies at the pre-, in- and post-processing stages.

Indeed, primary barriers to implementing improved environmental technologies and practices are economic factors (Hilson, 2000). Thus, an algorithm was developed to assess the economic and environmental performance of suggested bundles of improved technologies and practices. The assessment criteria were based on capital cost and benefits (i.e. production increases and generation of by-products, savings in energy and flux materials, and reduction in $\mathrm{SO}_{2}$ and slag). These criteria were formulated through the use of a multi-step procedure incorporating quantitative and qualitative evaluations. In essence, these bundles were rank ordered on the basis of the assessment algorithm in terms of potential improved environmental and economic performance as a function of smelter size (small, medium, large) and existing furnace type (reverberatory, blast, electric, and rotary high temperature furnaces). We compared four types of bundles for inclusion at the pre-processing stage, that is, (a) drying unit only, (b) drying and desulfurization units, (c) drying and hydro-metallurgical units, and (d) drying, desulfurization and hydro-metallurgical units. Typical practices in secondary lead smelting operations involve drying units at the pre-processing stage and to a lesser extent both drying and desulfurization units. As documented in Table 1, the drying unit added little improvement from both economic and environmental standpoint. The desulfurization unit contributed marginal improvement. The addition of hydro-metallurgical unit to drying significantly improved the bundle performance to a 'high' level for different furnace set-ups across all sizes of smelters and even to 'very high' level for the blast furnace set-up for small smelters.

As a significant cleaner technology, a hydro-metallurgical unit is highly efficient and produces significantly less amounts of emissions compared to pyro-metallurgical systems. The use of a hydrometallurgical system results in increased lead production, energy/ flux savings as well as significant reduction in $\mathrm{SO}_{2}$ and slag. This was evident for all smelter sizes and different types of high temperature furnace set-ups. The addition of desulfurization unit to the drying/ hydro-metallurgical combination marginally increased the performance to 'somewhat very high' (except for a blast furnace set-up for a small smelter). Therefore, it appears that the adoption of cleaner technologies at the pre-processing stage in secondary smelter operations can significantly improve the smelter performance from both economic and environmental perspectives. Consequently, future research should pursue these options among U.S. secondary lead smelters.

The limitations of this study should be acknowledged. First, the knowledge presented in this study is based on an evidence-based methodology. Although it is largely relying on the scientific literature and the experience of the authors, there is a need to further validate the findings with stakeholders in the universe of US secondary lead smelters. Second, we presented a model to integrate the criteria of cost and benefits in a single sustainable index. Although the outcomes of this index are consistent with the general views in the published literature, further validation is required on scientific grounds. Perhaps additional elements should be added to capital cost such as operating costs, an issue that will be examined in future research. Nonetheless, it seems a promising approach for managing complexity and comparing the performance of integrated environmental solutions for different options.

\section{Concluding remarks}

One can deduce from the findings of this study that it is technically and economically feasible to implement integrated environmental solutions to increase lead recovery and recycling among US smelters. The working example presented in this research can be confirmed with US stakeholders and form the basis for implementable solutions in the lead smelter and product industries to help reverse the overall trend of declining life-cycle recycling rates.

\section{Acknowledgments}

This study was supported by a grant from the US Environmental Protection Agency. This paper has not been subjected to the Agency's internal review. Therefore, the research results presented herein do not, necessarily, reflect the views of the Agency or its policies. The authors are indebted for the helpful comments made by the anonymous reviewers.

\section{Appendix A. Description of evidence for in-, pre- and post- processing technologies for secondary lead smelters}

Table A1

Description of evidence for characteristics of in-processing technologies in US recycling plants.

\begin{tabular}{|c|c|c|c|c|c|}
\hline Type of technology & Type of furnace & Technology description & $\begin{array}{l}\text { Furnace } \\
\text { efficiency }\end{array}$ & $\begin{array}{l}\text { Cost-effectiveness (energy } \\
\text { expenditure) (GJ/t of lead) }\end{array}$ & $\begin{array}{l}\text { Effectiveness } \\
\text { (purity of metal recovered) }\end{array}$ \\
\hline \multirow[t]{4}{*}{$\begin{array}{l}\text { Pyro-metallurgical } \\
\text { techniques }\end{array}$} & Blast furnace & $\begin{array}{l}\text { - Extracting lead via reaction of lead scrap and coke, } \\
\text { and subsequent oxidization }{ }^{1}\end{array}$ & $91-94 \%^{\mathrm{a}}$ & $5-11.86^{b}$ & $\begin{array}{l}82-94 \% \text { depending on } \\
\text { charge and reaction gases }\end{array}$ \\
\hline & Electric furnace & $\begin{array}{l}\text { - Extracting lead via melting and reaction of lead scrap, } \\
\text { fluxes and coke } \\
\text { - An electric arc produced between two electrodes is } \\
\text { used to heat the mix to the reaction temperature }\end{array}$ & $>99 \%$ & $2.98^{\mathrm{c}}$ & $>99.5 \% \mathrm{~b}$ \\
\hline & Rotary furnace & $\begin{array}{l}\text { - Extracting lead via reaction of lead scrap and coke, } \\
\text { and subsequent oxidization of coke with introduction } \\
\text { of fuel gases through tuyeres or burners }{ }^{\mathrm{d}}\end{array}$ & $98 \%^{\mathrm{e}}$ & $2.32^{\mathrm{f}}$ & $94-98 \%^{\mathrm{e}}$ \\
\hline & Reverberatory furnace & $\begin{array}{l}\text { - Extracting lead by reaction of lead scrap and flux by } \\
\text { introduction of reaction gases, fuel and fine materials } \\
\text { through top or wall mounted tuyeres }{ }^{f}\end{array}$ & $75-80 \%^{\mathrm{d}}$ & $2.13-2.47^{g}$ & $92-96 \%{ }^{\mathrm{f}}$ \\
\hline
\end{tabular}

Cost effectiveness is calculated as the energy spent per ton of metal recovered.

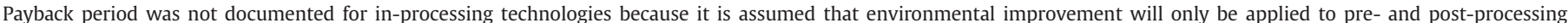
technologies to enhance the performance of in-processing technologies.

a From Ryzhenkov et al. (2006).

b From Ziebik and Stanek (2006).

c From Akihiko (2004).

d From USEPA (1998).

e From Zhang et al. (2008).

f From Rabah and Barakat (2001).

g From Akihiko (2004). 
Table A2

Description of evidence for characteristics of improved in-processing smelting technologies.

\begin{tabular}{|c|c|c|c|c|c|}
\hline Type of technology & Type of process & Technology description & $\begin{array}{l}\text { Efficiency } \\
\text { (process efficiency) }\end{array}$ & $\begin{array}{l}\text { Cost-effectiveness (energy } \\
\text { expenditure) (GJ/t of lead) }\end{array}$ & $\begin{array}{l}\text { Effectiveness (purity of } \\
\text { metal recovered) }\end{array}$ \\
\hline \multirow[t]{4}{*}{$\begin{array}{l}\text { Hydro-metallurgical } \\
\text { techniques }\end{array}$} & LEDCLOR & $\begin{array}{l}\text { - Metal content is leached into the solvent (diluted } \\
\text { ferric chloride) and extracted by electrowinning }\end{array}$ & $99.4-99.7 \%^{\mathrm{a}}$ & $1.8^{\mathrm{b}}$ & $97-99 \%^{\mathrm{a}}$ \\
\hline & Electrowinning acid & $\begin{array}{l}\text { - Metal content is leached into the solvent and } \\
\text { extracted by electrowinning }\end{array}$ & $98-99.5 \%$ & $1.8-3.28^{\mathrm{b}}$ & $99.98-99.99 \%$ b \\
\hline & $\begin{array}{l}\text { Electrowinning } \\
\text { basic }\end{array}$ & $\begin{array}{l}\text { - Metal content is leached into basic solvent and } \\
\text { extracted by electrowinning }{ }^{\mathrm{b}}\end{array}$ & $85-98 \%{ }^{b}$ & $1.4-1.8^{\mathrm{b}}$ & $99.98-99.99 \%{ }^{b}$ \\
\hline & PLINT & $\begin{array}{l}\text { - Intermediates from the electrowinning process } \\
\text { (lead hydroxide) are used as the feed to the kettle } \\
\text { (pyro-metallurgy) }^{c}\end{array}$ & $99.5^{\mathrm{c}}$ & $1.8-2.16^{\mathrm{d}}$ & $99.99 \%{ }^{c}$ \\
\hline \multirow[t]{5}{*}{$\begin{array}{l}\text { Pyro-metalurgical } \\
\text { techniques }\end{array}$} & Ausmelt & $\begin{array}{l}\text { - Technology is based on top entry into lance system, } \\
\text { delivering combustion gases, fuel and process air below } \\
\text { the surface of liquid slag bath }\end{array}$ & $95 \%{ }^{\mathrm{f}}$ & $0.36-1.44^{\mathrm{f}}$ & $98 \%{ }^{\mathrm{f}}$ \\
\hline & CX system & $\begin{array}{l}\text { - Use of desulphurization and rotary furnace to extract } \\
\text { lead from batteries }\end{array}$ & $86.50 \% \mathrm{~g}$ & $0.61^{\mathrm{h}}$ & $99.99 \%$ \\
\hline & ISASMELT & $\begin{array}{l}\text { - Technology is based on top entry into lance system, } \\
\text { delivering combustion gases, fuel and process air below } \\
\text { the surface of liquid slag bath }\end{array}$ & $>99 \% \mathrm{j}$ & $0.47^{k}$ & $\begin{array}{l}\text { Soft lead } 99.8 \% \text {, } \\
\text { Hard lead } 79.2 \%\end{array}$ \\
\hline & KIVCET & $\begin{array}{l}\text { - Based on combination of charge roasting and smelting } \\
\text { technologies in pulverized condition via use of oxygen } \\
\text { and electrosmelting }\end{array}$ & $98-98.3 \% 1$ & $1.33^{\mathrm{m}}$ & $94-96.5^{1}$ \\
\hline & $\begin{array}{l}\text { Top blown } \\
\text { rotary furnace }\end{array}$ & $\begin{array}{l}\text { - Based on rotating tilted furnace with introduction } \\
\text { (blowing) of oxygen and fuel gases via a lance }\end{array}$ & $98 \%^{\mathrm{n}}$ & $1.93^{\circ}$ & $94-98 \%^{\mathrm{p}}$ \\
\hline
\end{tabular}

a From Andrews et al. (2000).

b From Ferracin et al. (2002).

c From Frias et al. (2002).

d From Agrawal et al. (2004).

e From Baldock and Short (2000).

f From Hughes (2000).

g From Errington et al. (2005).

h From Engitec STE process (2008b).

i From Arthur and Edwards (2003).

j From Ramus and Hawkins (1993).

k From Xstrata (2006).

1 From Agrawal et al. (2004).

m From Akihiko (2004).

n From Ryzhenkov et al. (2006).

o From Rabah and Barakat (2001).

p From Ziebik and Stanek (2006).

- Payback period for improved in-processing technologies varies with the designed production capacity.

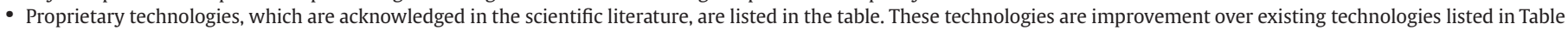
A1. LEDCLOR and PLINT technologies are the most widely accepted proprietary hydro-metallurgical technologies in the metal extraction industry. Electrowinning technologies have been implemented with some variations among smelters. Ausmelt, CX System, ISASMELT and KIVCET are improved proprietary pyro-metallurgical technologies which are variations of existing technologies. Top-blown rotary furnace is an improved technology currently in use in the US smelting industry.

Table A3

Description of evidence for characteristics of pre-processing US secondary lead smelting technologies.

\begin{tabular}{|c|c|c|c|c|c|c|c|}
\hline $\begin{array}{l}\text { Type of } \\
\text { technology }\end{array}$ & Type of process & Technology description & Efficiency & $\begin{array}{l}\text { Cost-effectiveness } \\
\text { (energy savings/ } \\
\text { expenditure) }\end{array}$ & $\begin{array}{l}\text { Payback } \\
\text { period } \\
\text { (years) }\end{array}$ & $\begin{array}{l}\text { Environmental } \\
\text { benefits }\end{array}$ & $\begin{array}{l}\text { Productivity } \\
\text { increase }\end{array}$ \\
\hline \multirow[t]{5}{*}{ Pre-processing } & $\begin{array}{l}\text { Battery breaking } \\
\text { and hydro- } \\
\text { separation }\end{array}$ & $\begin{array}{l}\text { - Scrapped batteries are crushed and } \\
\text { metal components and plastic casing } \\
\text { parts are density separated in water }\end{array}$ & $95 \%^{\mathrm{a}}$ & $\begin{array}{l}\text { Not } \\
\text { available }\end{array}$ & $3^{b}$ & $\begin{array}{l}\text { Reduction in } \\
\text { furnace } \\
\text { slag output }^{\mathrm{c}}\end{array}$ & None \\
\hline & Air separation & $\begin{array}{l}\text { - Scrapped lead containing parts are crushed and } \\
\text { metal components are separated from other } \\
\text { waste using compressed air }\end{array}$ & $\begin{array}{l}\text { Not } \\
\text { available }\end{array}$ & $\begin{array}{l}\text { Not } \\
\text { available }\end{array}$ & $\begin{array}{l}\text { Not } \\
\text { available }\end{array}$ & $\begin{array}{l}\text { Reduction in } \\
\text { furnace } \\
\text { slag output }^{\mathrm{C}}\end{array}$ & None \\
\hline & Roasting/ drying & $\begin{array}{l}\text { - Separated lead metal scrap is dried by passing } \\
\text { hot gases produced either from furnace } \\
\text { operations or separately }\end{array}$ & $85 \%{ }^{\mathrm{d}}$ & $3 \%$ savings $^{e}$ & $1^{\mathrm{e}}$ & None & None \\
\hline & Desulfurization & $\begin{array}{l}\text { - Battery paste separated during hydro-separation } \\
\text { is desulfurized by mixing it with sodium carbonate }\end{array}$ & $93 \% \mathrm{f}$ & $8-10 \%$ savings $^{\mathrm{g}}$ & $3^{\mathrm{b}}$ & $\begin{array}{l}75-80 \% \text { reduction } \\
\text { in } \mathrm{SO}_{2} \text { emissions }\end{array}$ & $\begin{array}{l}25-30 \% \text { increase in } \\
\text { smelter throughput }\end{array}$ \\
\hline & $\begin{array}{l}\text { Hydro-metallurgical } \\
\text { processing }\end{array}$ & $\begin{array}{l}\text { - Pure lead is extracted from battery paste or sludge } \\
\text { containing lead content by electro-winning process }\end{array}$ & $98-99.5 \%^{\mathrm{i}}$ & $10-12 \%$ savings $^{\mathrm{j}}$ & $3-4^{j}$ & $\begin{array}{l}>80 \% \text { in reduction } \\
\text { in } \mathrm{SO}_{2} \text { emissions }\end{array}$ & $\begin{array}{l}25-30 \% \text { increase in } \\
\text { smelter throughput }\end{array}$ \\
\hline
\end{tabular}

a From Abrams et al. (1999).

b From Wolters et al. (2008).

c Reduction in furnace slag generated is estimated at $\geq 10 \%$.

d From Warner et al. (2006).

e From Chakrabarti and Mitra (2005).

${ }^{\text {f }}$ From Lyakov et al. (2007).

g From Olympia Resource Limited (2005).

h From Missouri Department of Natural Resources Report (2005).

- Hydro-metallurgical processing is considered complementary to improve the performance of existing in-processing technology.

i From Ferracin et al. (2002).

j From the Environmental Technology Assessment Workshop Report (UNEP, 2000). 
Table A4

Description of evidence for characteristics of pollution prevention and control technologies.

\begin{tabular}{|c|c|c|c|c|c|c|c|}
\hline Type of control & Point of emission & Type of technology & Technology description & Efficiency & $\begin{array}{l}\text { Cost-effectiveness (energy } \\
\text { expenditure per volume } \\
\text { of gas flow) }\left(\mathrm{kWh} / \mathrm{Nm}^{3}\right)\end{array}$ & $\begin{array}{l}\text { Payback period } \\
\text { (years) }\end{array}$ & $\begin{array}{l}\text { Effectiveness (contaminant } \\
\text { concentration per volume of } \\
\text { treated gas) }\left(\mathrm{mg} / \mathrm{Nm}^{3}\right)\end{array}$ \\
\hline \multirow[t]{6}{*}{ Dust abatement } & \multirow[t]{6}{*}{ a,b,c,f,o,p } & Hot electrostatic precipitator & $\begin{array}{l}- \text { Particles are charged and subsequently separated mechanically } \\
\text { from gas stream by vibrating the collection electrodes }\end{array}$ & $>99 \%^{\mathrm{a}}$ & 1.27 & $3.5-4^{b}$ & $<5-15^{\mathrm{a}}$ \\
\hline & & Wet electrostatic precipitator & $\begin{array}{l}\text { - Particles are charged and separated from the gas stream. Settled dust } \\
\text { is flushed out of the collection electrodes by spraying suitable solution }\end{array}$ & $<99 \%$ & 1.27 & $3.5-4^{b}$ & $<1-5^{\mathrm{a}}$ \\
\hline & & Fabric or bag filters & $\begin{array}{l}\text { - Particles are separated by passing gas through a series of } \\
\text { fabric screens (bags) }\end{array}$ & $>99.5 \%^{\mathrm{a}}$ & $1.5 * 10^{-3}-4 * 10^{-3}$ & $2^{c}$ & $1-5^{\mathrm{a}}$ \\
\hline & & Wet scrubbers & $\begin{array}{l}\text { - Scrubbing liquid is sprayed on the gas passage path } \\
\text { to wet the particles and collect them in wetting liquid }\end{array}$ & $>80-99 \%^{\mathrm{a}}$ & $8.6 * 10^{-3}$ & $<1^{\mathrm{d}}$ & $4-50^{\mathrm{a}}$ \\
\hline & & Cyclones & $\begin{array}{l}\text { - Particles are separated by changing the direction of gas flow, } \\
\text { thus, separating heavier particles }\end{array}$ & $40 \%$ & NA & $1-3^{e}$ & $100-300^{\mathrm{a}}$ \\
\hline & & Ceramic filters & $\begin{array}{l}\text { - Particles are separated by forcing the gas through a series } \\
\text { of ceramic filter candles }\end{array}$ & $99.50 \%^{\mathrm{a}}$ & $1.5 * 10^{-3}-4 * 10^{-3}$ & $2-2.5^{\mathrm{a}}$ & $0.1-1^{\mathrm{a}}$ \\
\hline Gas burning & $\mathrm{n}$ & After burners & $\begin{array}{l}\text { - The gas is heated to suitable temperature to } \\
\text { oxidize or decompose excess/low concentration of hazardous gases }\end{array}$ & $98 \%^{\mathrm{d}}$ & $2.7 * 10^{-4}-6 * 10^{-4}$ & $1-2.2^{\mathrm{d}}$ & $<5-15^{\mathrm{a}}$ \\
\hline \multirow[t]{2}{*}{ Gas scrubbing systems } & \multirow[t]{2}{*}{$\mathrm{g}, \mathrm{h}, \mathrm{l}, \mathrm{m}$} & Wet scrubbing & $\begin{array}{l}\text { - Scrubbing liquid is sprayed on the gas passage path. The gas is } \\
\text { held in the scrubbing chamber till acceptable level of precipitation } \\
\text { occurs. The gas molecules react with the media and } \\
\text { precipitate or combine to form useful by-products }\end{array}$ & $>80-99 \%^{\mathrm{a}}$ & $4.2 * 10^{-4}$ & $<1^{\mathrm{d}}$ & $<50-200^{1}$ \\
\hline & & Dry and semidry scrubbing & $\begin{array}{l}\text { - Gas is passed through scrubbing medium (solid or slurry) } \\
\text { to capture the molecules in the medium }\end{array}$ & $>80-99 \%^{1}$ & $1.6^{*} 10^{-4}$ & $<1^{4}$ & $<50-200^{\mathrm{a}}$ \\
\hline Effluent (water) & \multirow[t]{3}{*}{$\mathrm{E}$} & Process integrated measures & & & & & \\
\hline \multirow[t]{9}{*}{ Treatment } & & Recycling & - Recirculation of effluent water in the process where it is generated & NA & NA & NA & NA \\
\hline & & Reuse & $\begin{array}{l}\text { - Redirecting effluent water generated in one process } \\
\text { for use in other processes }\end{array}$ & NA & NA & NA & NA \\
\hline & \multirow[t]{7}{*}{$\mathrm{J}$} & End-of-pipe measures & & & & & \\
\hline & & Chemical precipitation & $\begin{array}{l}\text { - Soluble metal ions are separated by adding reagents to form insoluble } \\
\text { compounds and forcing them to precipitate in holding tanks }\end{array}$ & $>99.5 \%$ & 6.25 & $1.5-2^{\mathrm{a}}$ & $<0.1^{\mathrm{a}}$ \\
\hline & & Sedimentation & $\begin{array}{l}\text { - Solid (heavier) particles are separated from effluent water by } \\
\text { holding waste water in tanks and allowing solids to precipitate }\end{array}$ & Up to $99 \%^{a}$ & 6.25 & $1-2^{\mathrm{a}}$ & $<0.1^{\mathrm{a}}$ \\
\hline & & Filtration & $\begin{array}{l}\text { - Effluent water is passed trough filter media (media bed) to separate } \\
\text { toxic substances before releasing into holding tanks or water streams }\end{array}$ & Up to $99 \%^{\text {a }}$ & 6.25 & $1-2^{\mathrm{a}}$ & $<0.1^{\mathrm{a}}$ \\
\hline & & Flotation & $\begin{array}{l}\text { - Light density effluent particles are separated from effluent water } \\
\text { by holding waste water in tanks and injecting (bubbling) air in } \\
\text { water forcing material to float }\end{array}$ & Up to $99 \%$ a & 6.25 & $1-1.5^{\mathrm{a}}$ & $<0.1^{\mathrm{a}}$ \\
\hline & & Electrolysis & $\begin{array}{l}\text { - Effluent water is stored in electrolytic cell and metals are } \\
\text { separated by applying a potential between electrodes }\end{array}$ & $>99.5 \%^{\mathrm{a}}$ & 6.25 & $2-3^{a}$ & $<0.1^{\mathrm{a}}$ \\
\hline & & Ion exchange & $\begin{array}{l}\text { Effluent water is passed through a column matrix of ion } \\
\text { exchange resins to absorb selective metal ions }\end{array}$ & $>99.5 \%^{\mathrm{a}}$ & 6.25 & $2-2.5^{\mathrm{a}}$ & $<0.1^{\mathrm{a}}$ \\
\hline
\end{tabular}

a From the European Commission Report (2007).

b From PT Seman Pandang (2006).

crom Chakrabarti and Mitra (2005).

d From Kenson (2005).

e From Saman and Nutter (1994).

- NA - not applicable.

- Please consult Fig. 4a for points of emission in pyro-metallurgical-based smelting process.

- The values obtained for cost-effectiveness were extracted fro the European Commission Report (2007). 
Appendix B. Environmental improvement in lead smelting practices and technologies

\section{Level I}
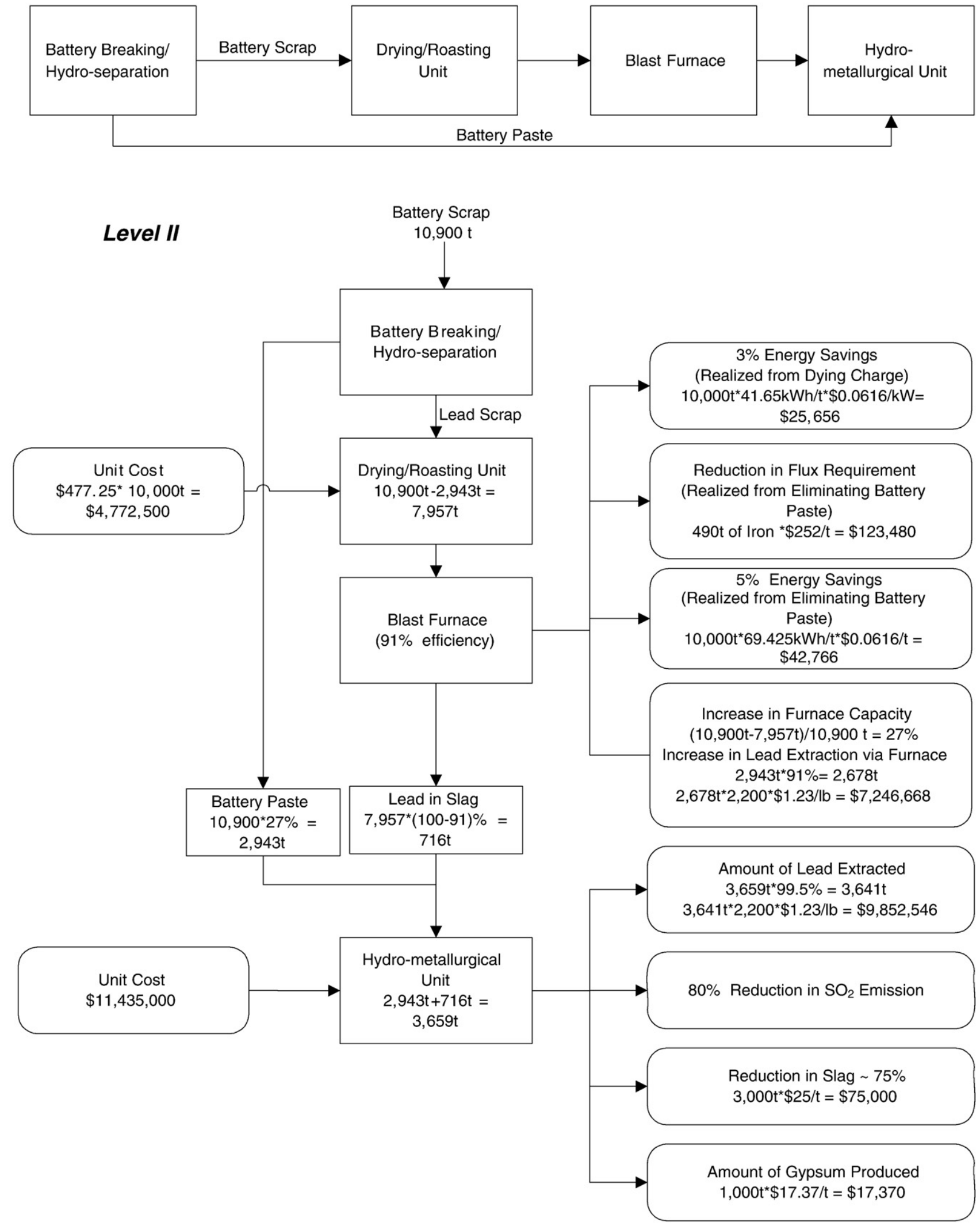

Fig. B1. Improvement for blast furnace - small smelter (10,000 t/year). 


\section{Level I}
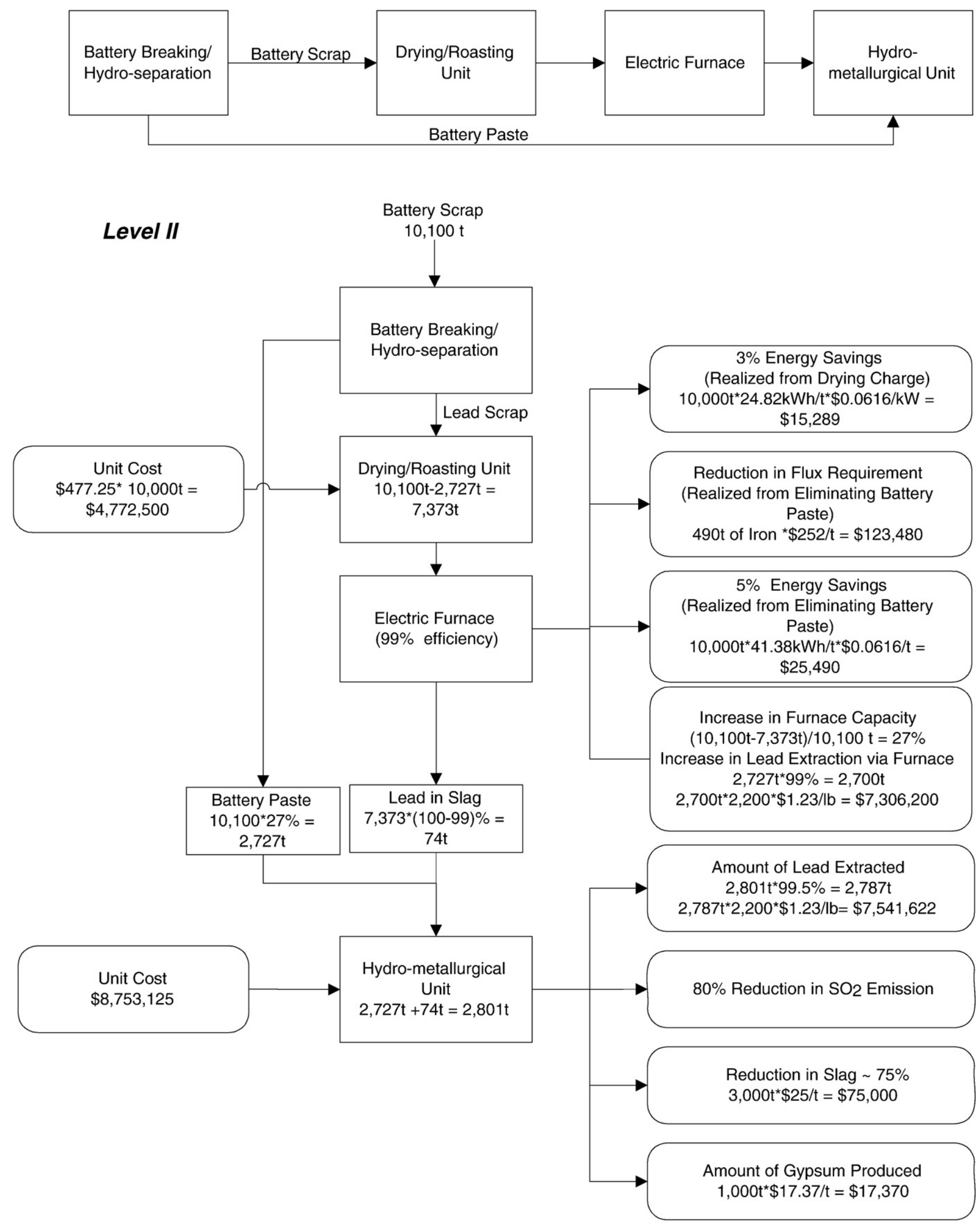

Fig. B2. Improvement for electric furnace - small smelter (10,000 t/year). 


\section{Level I}
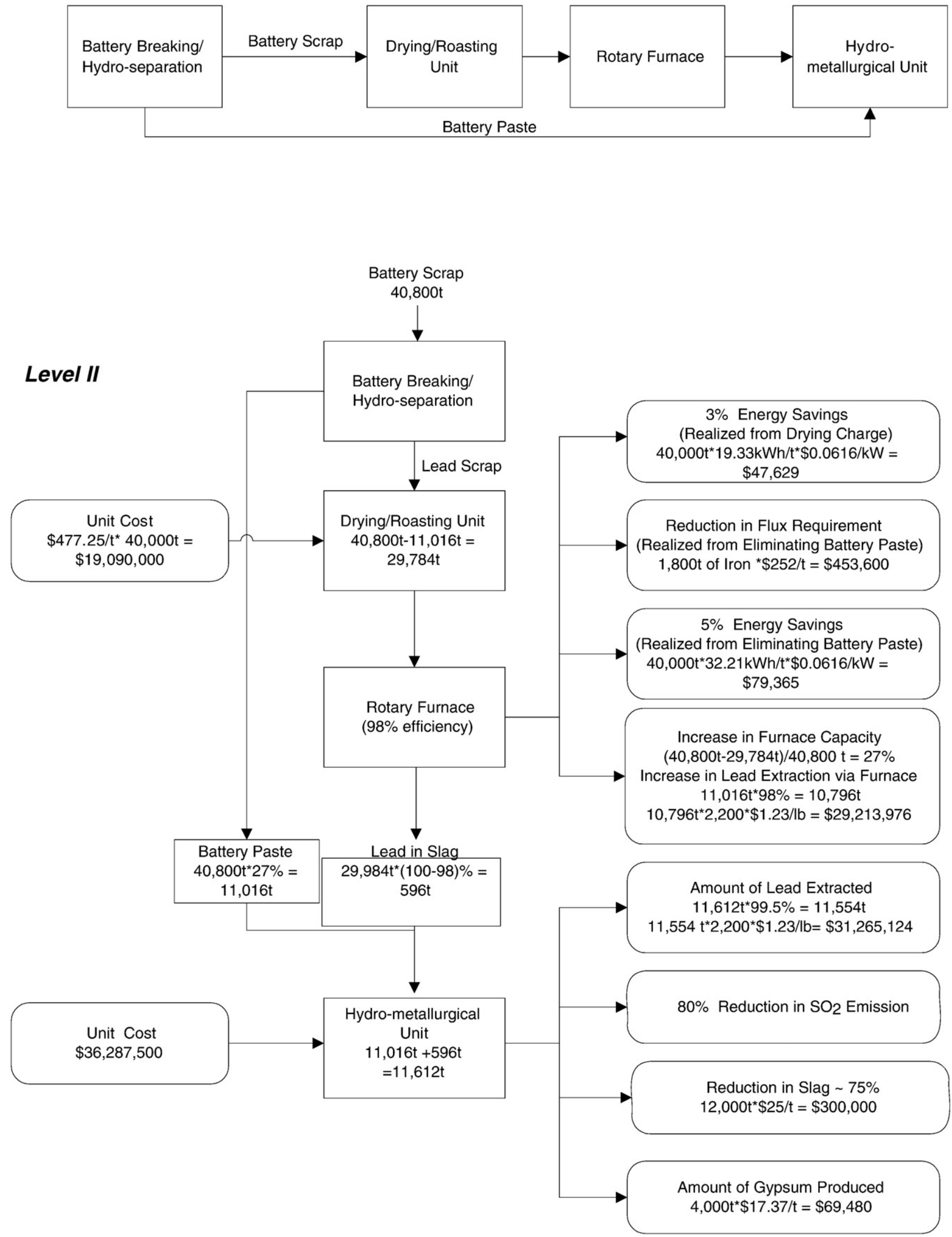

Fig. B3. Rotary furnace - medium smelter (40,000 t/year). 


\section{Level I}
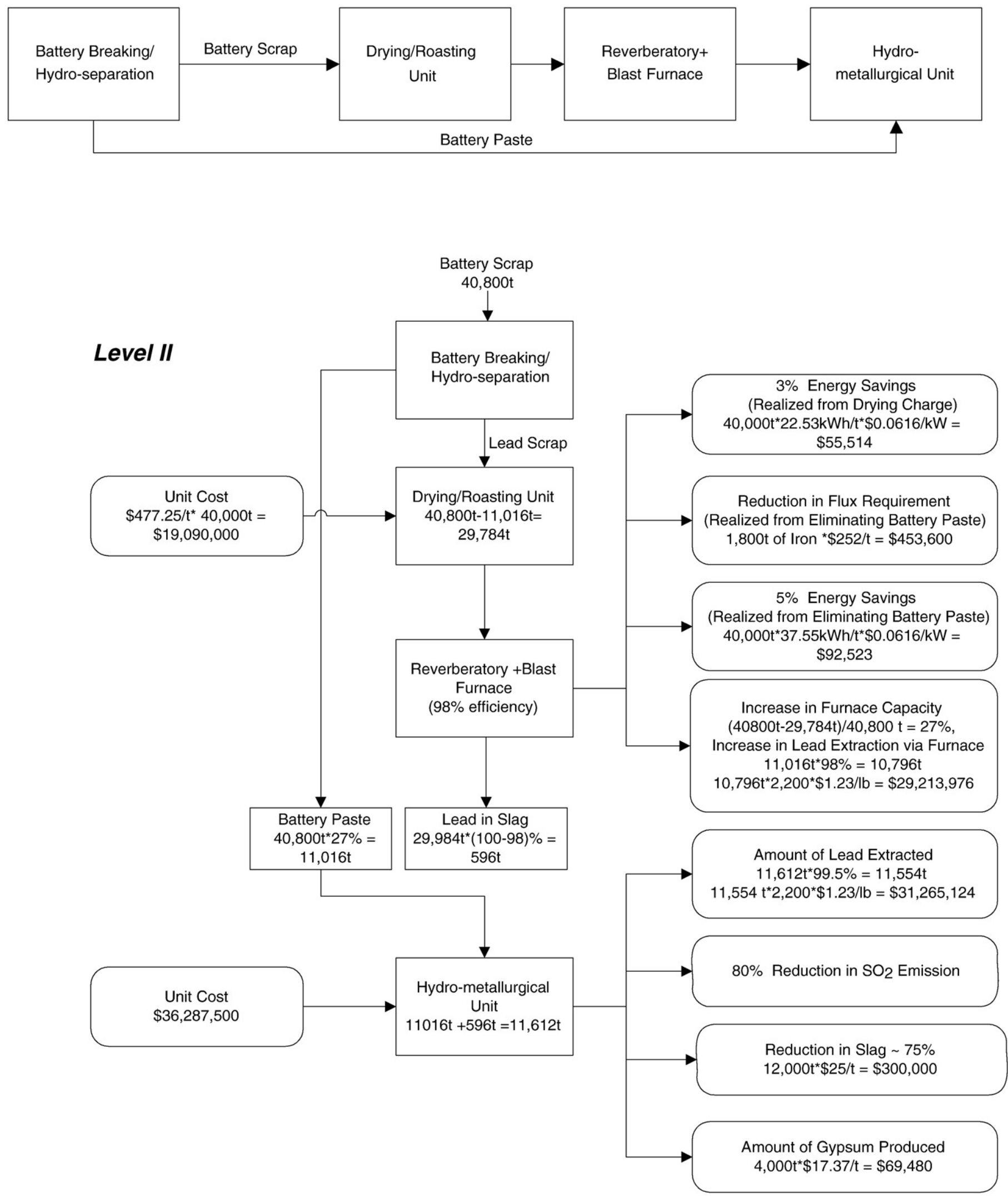

Fig. B4. Reverberatory and blast furnaces - medium smelter (40,000 t/year). 


\section{Level I}

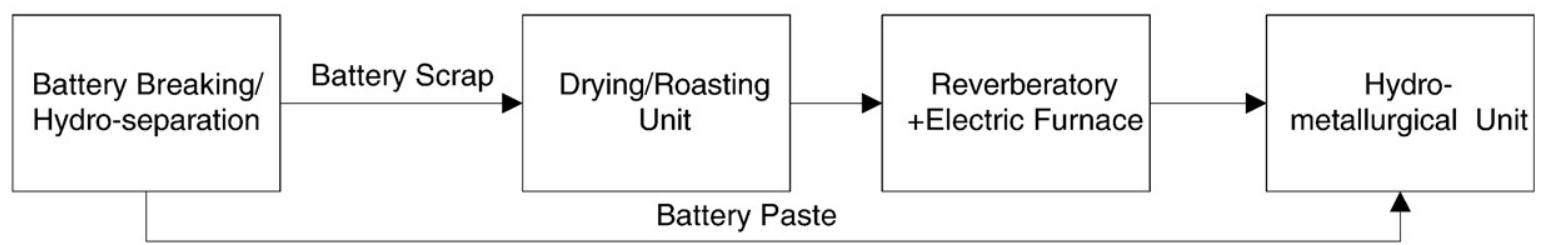

\section{Level II}

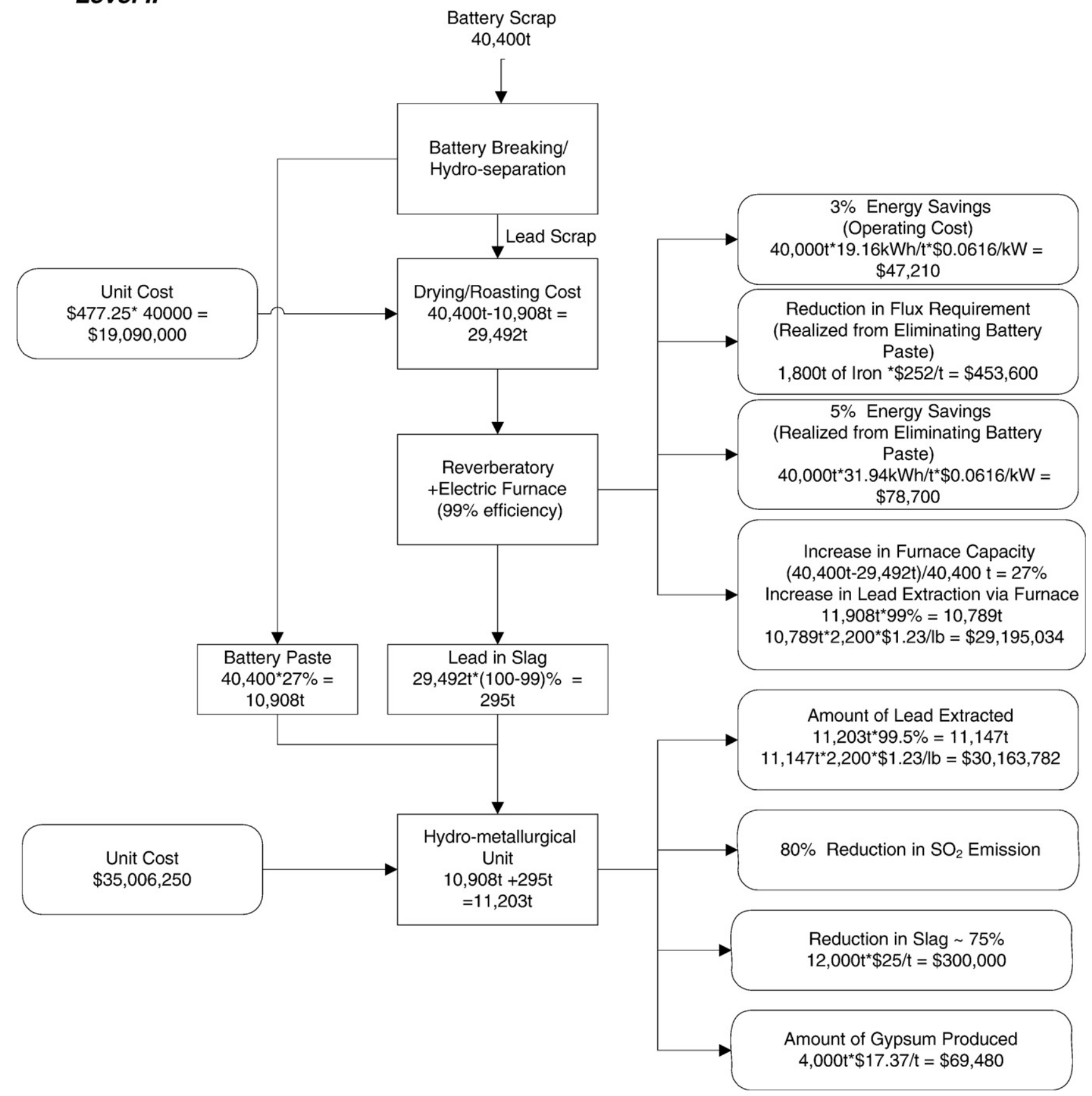

Fig. B5. Reverberatory and electric furnaces - medium smelter (40,000 t/year). 


\section{Level I}
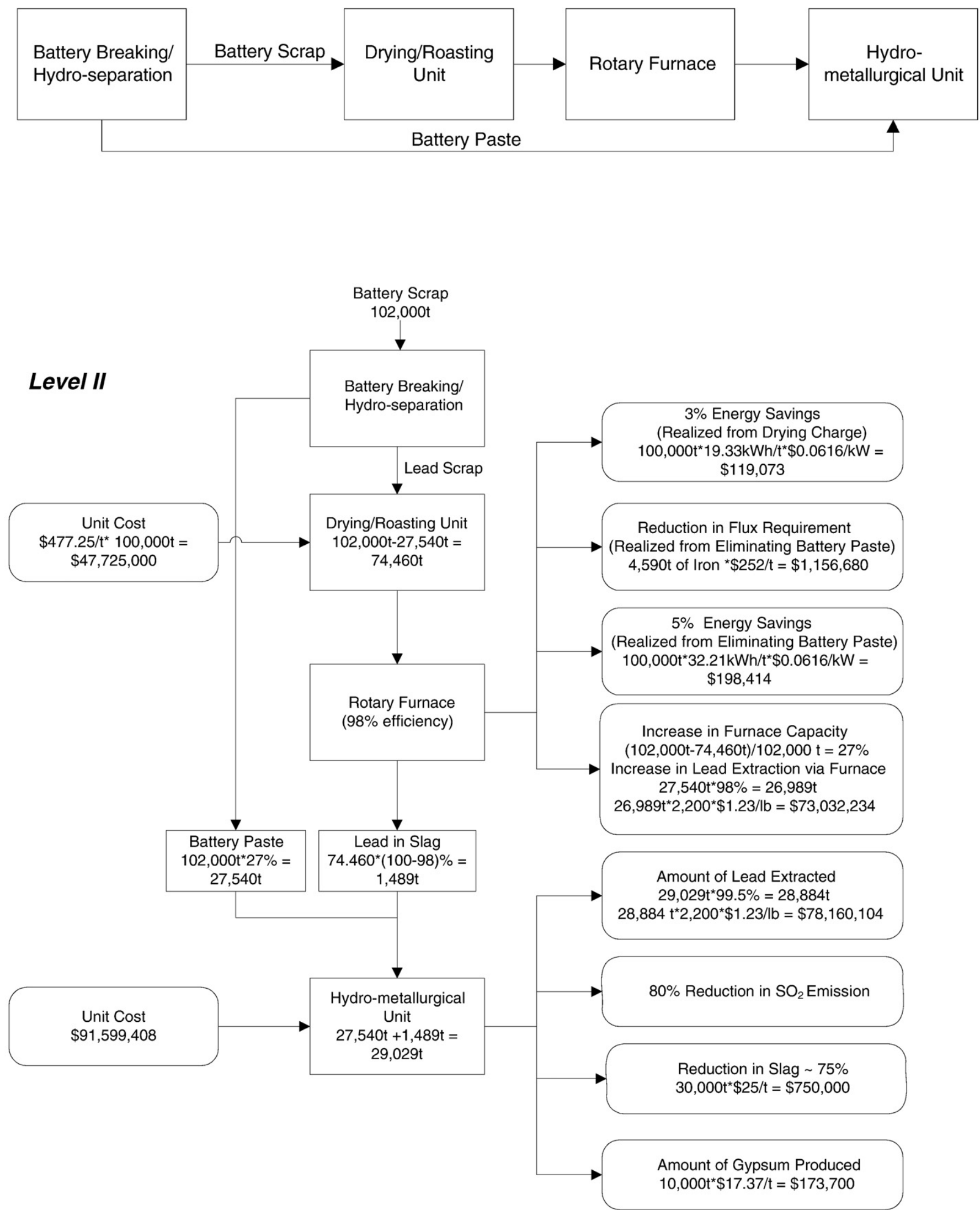

Fig. B6. Rotary furnace - large smelter (100,000 t/year). 


\section{Level I}
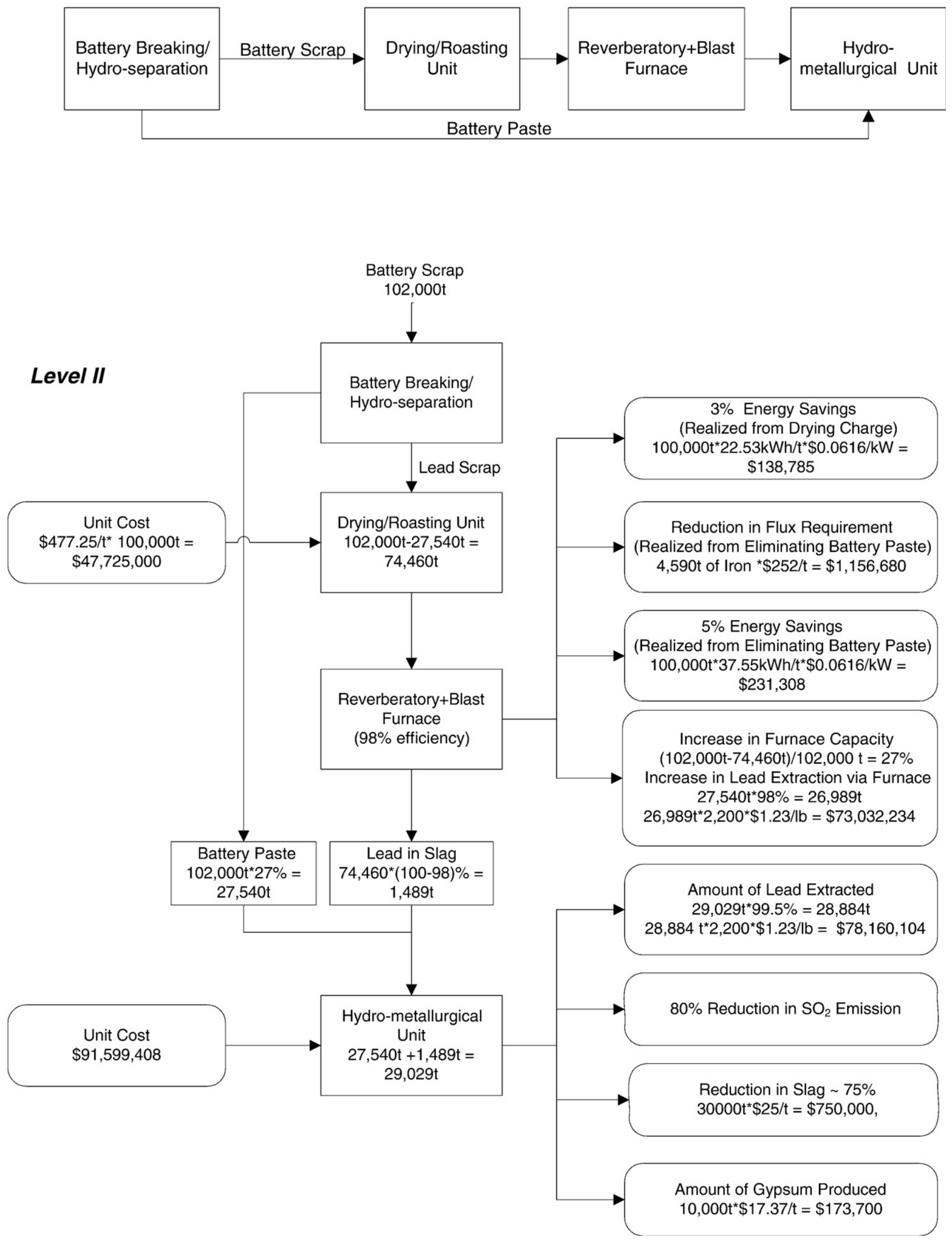

Fig. B7. Reverberatory and blast furnaces - large smelter (100,000 t/year). 


\section{Level I}
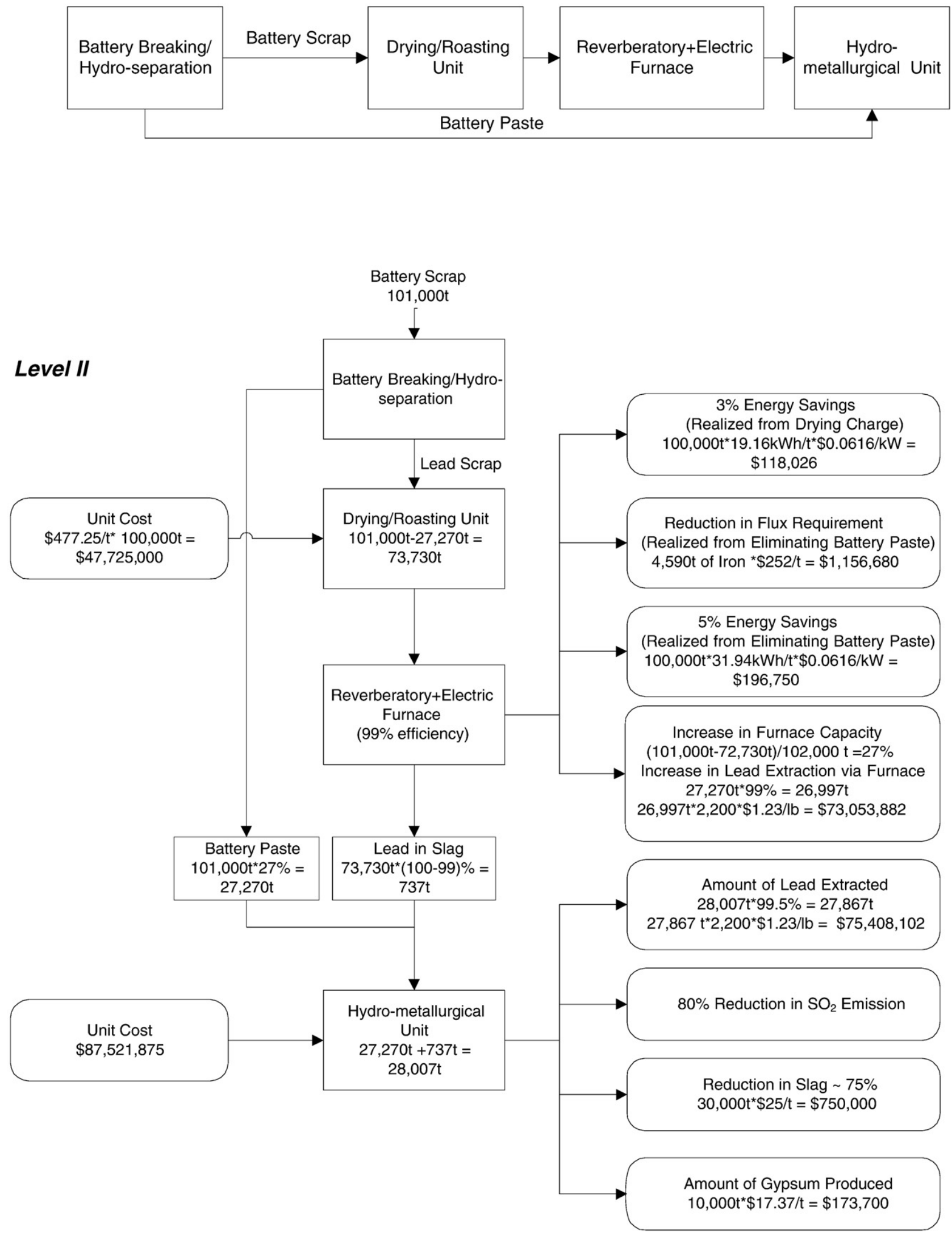

Fig. B8. Reverberatory and electric furnaces - large smelter (100,000 t/year). 
Footnote:

${ }^{1}$ Smelter capacity is assumed $10,000 \mathrm{t}$ for small, $40,000 \mathrm{t}$ for medium and $100,000 \mathrm{t}$ for large smelters. The estimation is based on the industry characterization of smelters.

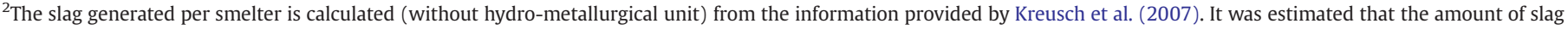

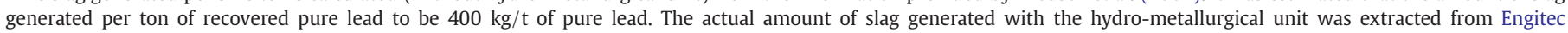
Technologies (2008a). With the added features of the above technology bundle, it is assumed that it will closely resemble the CX system.

${ }^{3}$ The cost of acquiring a drying/roasting unit with installation/modifications is estimated to be $\$ 477.25 / \mathrm{t}$ (European Commission, 2001).

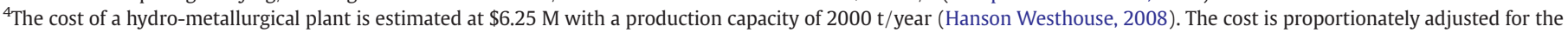
requirement of each scenario.

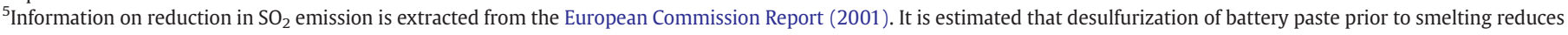
$\mathrm{SO}_{2}$ emissions by $80 \%$.

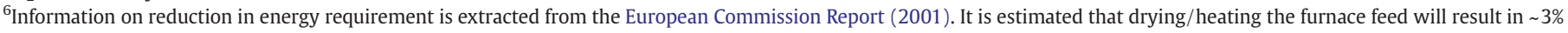
in energy savings. The cost of energy is obtained from Energy Information Administration.

${ }^{7}$ Information on blast furnace efficiency is extracted from Ryzhenkov et al. (2006)

${ }^{8}$ Information on electric furnace efficiency is extracted from Ziebik and Stanek (2006).

${ }^{9}$ Information on rotary furnace efficiency is extracted from Akihiko (2004).

${ }^{10}$ Information on reverberatory furnace efficiency is extracted from Zhang et al. (2008).

${ }^{11}$ The efficiency of reverberatory + blast furnace is calculated as: $80 \%$ reverberatory furnace efficiency $+(20 \% * 91 \%)$ for blast furnace efficiency.

${ }^{12}$ The efficiency of reverberatory +electric furnace is calculated as; $80 \%$ reverberatory furnace efficiency $+(20 \% * 99 \%)$ for electric furnace efficiency.

${ }^{13}$ Information on energy expenditure per ton of lead for a blast furnace is extracted from Ziebik and Stanek (2006).

${ }^{14}$ Information on energy expenditure per ton of lead for an electric furnace is extracted from Akihiko (2004).

${ }^{15}$ Information on energy expenditure per ton of lead for a rotary furnace is extracted from Rabah and Barakat (2001).

${ }^{16}$ Information on energy expenditure per ton of lead for a blast furnace is extracted from Akihiko (2004).

${ }^{17}$ The price per pound of lead was extracted from the Smith (2008). It is reported as $\$ 1.23 / \mathrm{lb}$.

${ }^{18}$ The price per ton of iron was extracted from the Fenton (2008). It is reported as $\$ 252 / \mathrm{t}$.

${ }^{19}$ The price per ton for gypsum was extracted from the Olson (2008). It is reported as $\$ 17.37 / \mathrm{t}$.

${ }^{20}$ The price per ton of slag disposal was extracted from the State of Idaho (2004). It is reported as hazardous waste disposal fees is $\$ 25 / \mathrm{t}$.

\section{Appendix C. Environmental improvement in lead smelting practices and technologies via changes in pre-processing stage}

\begin{tabular}{|c|c|c|c|c|c|c|}
\hline Type & $\begin{array}{l}\text { Technology/ } \\
\text { practice bundles }\end{array}$ & Benefits & Cost & Benefit & Compatibility & Comments \\
\hline \multirow[t]{4}{*}{ Blast } & $\begin{array}{l}\mathrm{U} 1+\mathrm{A} 2 \\
\mathrm{U} 1+\mathrm{A} 2+\mathrm{U} 3+ \\
\mathrm{U} 4+\mathrm{U} 5\end{array}$ & $\begin{array}{l}\cdot 91-94 \% \text { efficiency } \\
\cdot 98 \% \text { efficiency } \\
\text { - } 8-10 \% \text { energy savings } \\
\text { - } 5-6 \text { years payback period } \\
\text { - }>80 \% \text { reduction in } \mathrm{SO}_{2} \text { emission } \\
\text { - 25-30\% more throughput } \\
\text { - Commercial grade } \mathrm{Na}_{2} \mathrm{SO}_{4} \\
\text { - Reduction in slag generated }\end{array}$ & $\begin{array}{l}- \\
\text { High }\end{array}$ & $\begin{array}{l}- \\
\text { Very High }\end{array}$ & $\begin{array}{l}- \\
\text { Very High }\end{array}$ & $\begin{array}{l}\text { - } \\
\text { - High in efficiency } \\
\text { - Little/no energy savings } \\
\text { - Somewhat moderate payback period } \\
\text { - Increased environmental benefit } \\
\text { - Increased productivity } \\
\text { - High in efficiency } \\
\text { - Little/no energy savings }\end{array}$ \\
\hline & $\mathrm{U} 1+\mathrm{A} 2+\mathrm{U} 3+\mathrm{U} 5$ & $\begin{array}{l}\cdot 98 \% \text { efficiency } \\
\cdot 10-12 \% \text { energy savings } \\
\text { - } 4-5 \text { years payback period } \\
\cdot>80 \% \text { reduction in } \mathrm{SO}_{2} \text { emission } \\
\cdot 25-30 \% \text { more throughput } \\
\text { - Reduction in slag generated }\end{array}$ & High & Very High & Very High & $\begin{array}{l}\text { - High in efficiency } \\
\text { - Moderate energy savings } \\
\text { - Somewhat moderate payback period } \\
\text { - Increased environmental benefit } \\
\text { - Increased productivity }\end{array}$ \\
\hline & $\mathrm{U} 1+\mathrm{A} 2+\mathrm{U} 3+\mathrm{U} 4$ & $\begin{array}{l}\cdot \text { - } 91-94 \% \text { efficiency } \\
\cdot 3 \% \text { energy savings } \\
\text { - } 3.5 \text { years payback period } \\
\cdot 75-80 \% \text { reduction in } \mathrm{SO}_{2} \text { emission } \\
\text { - } 25-30 \% \text { more throughput } \\
\text { - Reduction in slag generated } \\
\text { - Commercial grade } \mathrm{Na}_{2} \mathrm{SO}_{4}\end{array}$ & Very Low & $\begin{array}{l}\text { Somewhat } \\
\text { Moderate }\end{array}$ & $\begin{array}{l}\text { Somewhat } \\
\text { Moderate }\end{array}$ & $\begin{array}{l}\text { - Moderate in efficiency } \\
\text { - Little/no energy savings } \\
\text { - Somewhat moderate payback period } \\
\text { - Increased environmental benefit } \\
\text { - Increased productivity }\end{array}$ \\
\hline & $\mathrm{U} 1+\mathrm{A} 2+\mathrm{U} 3$ & $\begin{array}{l}\cdot 91-94 \% \text { efficiency } \\
\text { - } 1 \text { year payback period } \\
\text { - } 3 \% \text { energy savings }\end{array}$ & Very Low & Very Low & Low & $\begin{array}{l}\text { - Moderate in efficiency } \\
\text { - Little/no energy savings } \\
\text { - Moderate payback period } \\
\text { - No environmental benefit } \\
\text { - No increase in productivity }\end{array}$ \\
\hline \multirow[t]{4}{*}{ Electric } & $\mathrm{U} 1+\mathrm{A} 3$ & • 99\% efficiency & - & - & - & - \\
\hline & $\begin{array}{l}\mathrm{U} 1+\mathrm{A} 3+\mathrm{U} 3+ \\
\mathrm{U} 4+\mathrm{U} 5\end{array}$ & $\begin{array}{l}\cdot 99 \% \text { efficiency } \\
\cdot 8-10 \% \text { energy savings } \\
\text { - } 5-6 \text { Yrs payback period } \\
\cdot>80 \% \text { reduction in } \mathrm{SO}_{2} \text { emission } \\
\text { - } 25-30 \% \text { more throughput } \\
\text { - Commercial grade } \mathrm{Na}_{2} \mathrm{SO}_{4} \\
\text { - Reduction in slag generated }\end{array}$ & Moderate & $\begin{array}{l}\text { Somewhat } \\
\text { Very High }\end{array}$ & $\begin{array}{l}\text { Somewhat } \\
\text { Very High }\end{array}$ & $\begin{array}{l}\text { - High in efficiency } \\
\text { - Little/no energy savings } \\
\text { - Somewhat moderate payback period } \\
\text { - Increased environmental benefit } \\
\text { - Increased productivity }\end{array}$ \\
\hline & $\mathrm{U} 1+\mathrm{A} 3+\mathrm{U} 3+\mathrm{U} 5$ & $\begin{array}{l}\cdot>99 \% \text { efficiency } \\
\cdot 10-12 \% \text { energy savings } \\
\cdot 4-5 \text { years payback period } \\
\cdot>80 \% \text { reduction in } \mathrm{SO}_{2} \text { emission } \\
\cdot 25-30 \% \text { more throughput } \\
\text { - Reduction in slag generated }\end{array}$ & Moderate & High & High & $\begin{array}{l}\text { - Very high in efficiency } \\
\text { - Moderate energy savings } \\
\text { - Somewhat moderate payback period } \\
\text { - Increased environmental benefit } \\
\text { - Increased productivity }\end{array}$ \\
\hline & $\mathrm{U} 1+\mathrm{A} 4+\mathrm{U} 3+\mathrm{U} 4$ & $\begin{array}{l}\cdot 99 \% \text { efficiency } \\
\cdot 3 \% \text { energy savings } \\
\cdot 3.5 \text { years payback period } \\
\cdot 75-80 \% \text { reduction in } \mathrm{SO}_{2} \text { emission } \\
\cdot 25-30 \% \text { more throughput }\end{array}$ & Very Low & $\begin{array}{l}\text { Somewhat } \\
\text { Moderate }\end{array}$ & $\begin{array}{l}\text { Somewhat } \\
\text { Moderate }\end{array}$ & $\begin{array}{l}\text { - High in efficiency } \\
\text { - Little/no energy savings } \\
\text { - Somewhat moderate payback period } \\
\text { - Increased environmental benefit } \\
\text { - Increased productivity }\end{array}$ \\
\hline
\end{tabular}


Appedix C (continued)

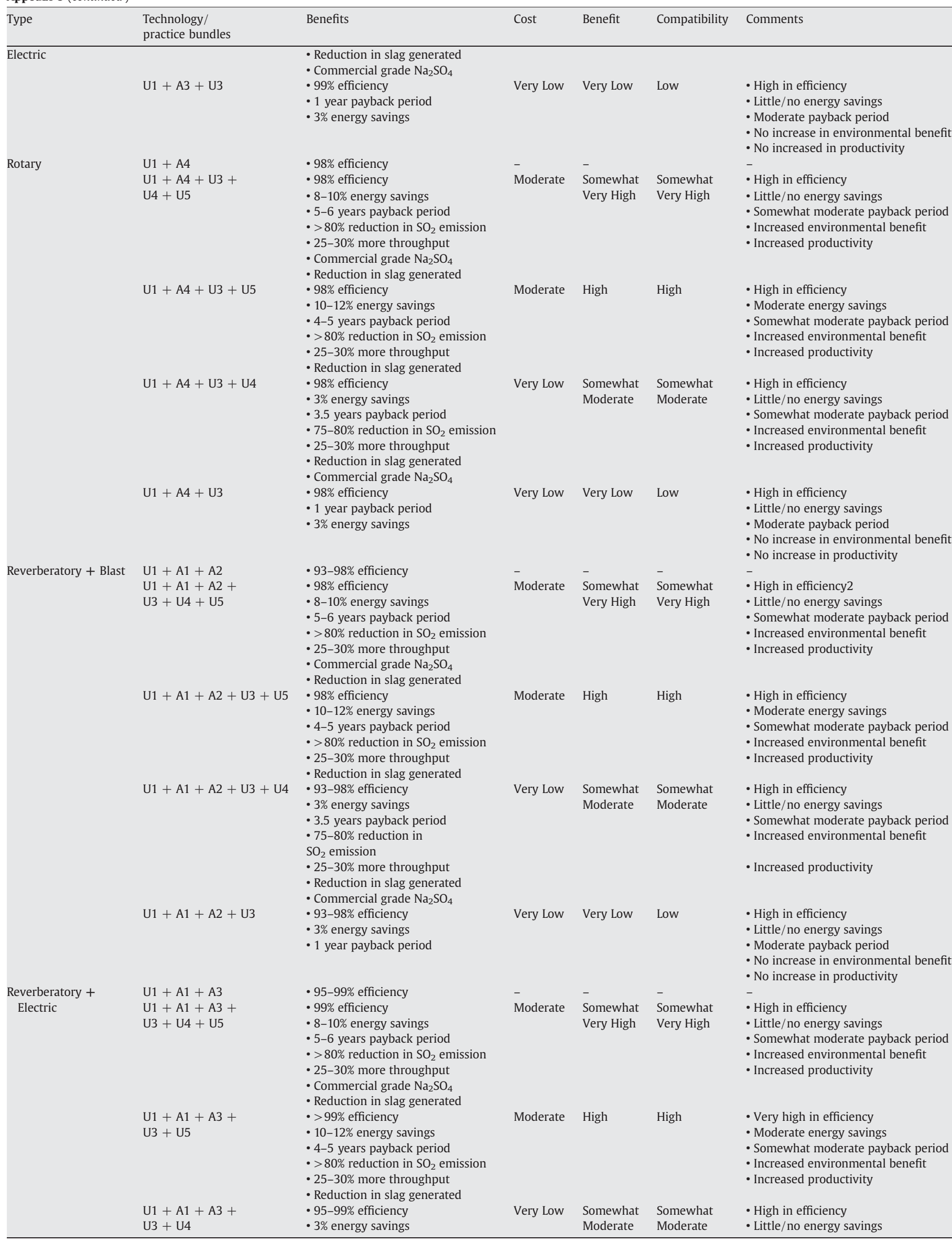


Appedix C (continued)

\begin{tabular}{|c|c|c|c|c|c|c|}
\hline Type & $\begin{array}{l}\text { Technology/ } \\
\text { practice bundles }\end{array}$ & Benefits & Cost & Benefit & Compatibility & Comments \\
\hline \multirow[t]{2}{*}{$\begin{array}{l}\text { Reverberatory + } \\
\text { Electric }\end{array}$} & & $\begin{array}{l}\text { - } 3.5 \text { years payback period } \\
\text { - } 75-80 \% \text { reduction in } \mathrm{SO}_{2} \text { emission } \\
\text { - 25-30\% more throughput } \\
\text { - Reduction in slag generated } \\
\text { - Commercial grade } \mathrm{Na}_{2} \mathrm{SO}_{4}\end{array}$ & & & & $\begin{array}{l}\text { - Somewhat moderate payback period } \\
\text { - Increased environmental benefit } \\
\text { - Increased productivity }\end{array}$ \\
\hline & $\mathrm{U} 1+\mathrm{A} 1+\mathrm{A} 3+\mathrm{U} 3$ & $\begin{array}{l}\cdot 95-99 \% \text { efficiency } \\
\cdot 3 \% \text { energy savings } \\
\text { - } 1 \text { year payback period }\end{array}$ & Very Low & Very Low & Low & $\begin{array}{l}\text { - High in efficiency } \\
\text { - Little/no energy savings } \\
\text { - Moderate payback period } \\
\text { - No increase in environmental benefit } \\
\text { - No increase in productivity }\end{array}$ \\
\hline
\end{tabular}

Footnote:

- Appendix C is constructed based on input information from Tables A1 and A3 in Appendix A.

- It is assumed that there are no changes in in-processing technologies.

- Only pre-processing technologies and processes are considered for environmental improvement management.

- The most significant benefits are only reported for technology bundles.

- U1 - Battery breaking and hydro-separation.

- U2 - Air separation of metal and non-metallic components.

- U3 - Drying of lead scrap extracted from hydro-separation.

- U4 - Desulfurization of battery paste for lead extraction.

- U5 - Hydro-metallurgical processing of slag, battery paste and sludge.

- A1 - Reverberatory furnace.

- A2 - Blast furnace.

- A3 - Electric furnace.

- A4 - Rotary furnace.

\section{References}

Abrams IM, Aulenbach DB, Bingham EC, Bollyky LJ, Brown Jr TF, Bruch B, et al. Removing specific water contaminants. In: Liu DHF, Liptak BG, editors. Environmental Engineer's Handbook. CRC Press LLC; 1999. p. 8.1-7.

Agrawal A, Kanta Sahu K, Pandey BD. Recent trends and current practices for secondary processing of zinc and lead. Part I: lead recovery from secondary sources. Waste Manage Res 2004;22:240-8.

Akihiko A. Effective energy utilization on Japanese copper smelters. Japan: Sumitomo metal mining co. Itd.; 2004. p. 1-10.

Andrews D, Raychaudhuri A, Frias C. Environmentally sound technologies for recycling secondary lead. J Power Sources 2000;88:124-9.

Arthur P, Edwards J. ISASMELT - a quiet revolution. Paper presented at EMC; 2003. p. 1-18.

Baldock BR, Short WE. Australian technology on the world scene - update on Ausmelt plants and projects. MINPREX 2000:169-75.

Barakat MA. Recovery of lead, tin and indium from alloy wire scrap. Hydrometallurgy 1998;49:63-73.

Bourson J. Recycling of lead/acid batteries in a small plant. J Power Sources 1995;57:81-3.

Bunge J, Cohen-Rosenthal E, Ruiz-Quintanilla A. Employee participation in pollution reduction: preliminary analysis of toxic release inventory. J Clean Prod 1996;4 (1):9-16.

De-Bruijn TJNM, Coenen FHJM, Lulofs KRD. Pollution prevention projects in Netherlands. J Clean Prod 1996:4(1):41-53.

Carlin JF, Smith GR, Bi X. Lead: US. Geological Survey Minerals Yearbook. United States Geological survey; 2006. p. 42.1-42.22.

Chaaban FB, Nuwayhid I, Djoundourian S. A study of social and economic implications of mobile sources on air quality in Lebanon. Transp Environ 2001;6:347-55.

Chakrabarti S, Mitra N. Economic and environmental impacts of pollution control regulation on small industries: a case study. Ecol Econ 2005;54:53-66.

Cow-perthwaite J, Dugdale PJ, Landry CJF, Morris DR, Steward FR, Wilson TCW. Energy aspects of a lead blast furnace. Metall Trans 1980;11B:291-9.

Coya B, Maran ón E, Sastre H. Ecotoxicity assessment of slag generated in the process of recycling lead from waste batteries. Resour Conserv Recyc 2000;29:291-300.

De Angelis G, Medici F, Montereali MR, Pietrelli L. Reuse of residues arising from lead batteries recycle: a feasibility study. Waste Manage 2002;22:925-30.

Diaz G, Martin D, Frias C, Sanchez F. Emerging applications of ZINCEX and PLACID technologies. J Miner 2001:53:30-1.

Dahodwalla $\mathrm{H}$, Heart S. Cleaner production options for lead-acid battery manufacturing Industry. J Clean Prod 2000;8:133-42.

Driussi C, Jansz J. Technological options for waste minimization in the mining industry. J Clean Prod 2006;14:682-8.

El-Halwagi MM. Pollution prevention through process integration. Clean Prod Processes 1998:1:5-19.

Energy Information Administration. Official Energy Statistics for U.S. Government Accessed on June 30, 2008 at http://www.eia.doe.gov/cneaf/electricity/epa/ epat7p4.html.

Engitec Technologies (a). "The integrated CX system- From scrap acid batteries to soft lead and lead alloys. Novate Milanese (MI) - Italy. Accesses on 5/24/2008 at http://www.engitec.com/PDF/CXSYSTEM.pdf.

Engitec Technologies (b). "Engitec STE process." Novate Milanese (MI) - Italy. Accesses on 5/24/2008 at http://www.engitec.com/PDF/STE.pdf.
Ettler V, Johan Z, Baronnet A, Jankovsky F, Gilles C, Mihaljevic M, et al. Mineralogy of airpollution-control residues from a secondary lead smelter: environmental implications. Environ Sci Technol 2005;39:9309-16.

Errington B, Arthur P, Wang J, Dong Y. The ISA-YMG lead smelting process. Paper presented at PbZn 2005 conference, Kyoto, Japan; 2005. p. 1-14.

Espinosa DCR, Bernardes AM, Tenório JAS. Brazilian policy on battery disposal and its practical effects on battery recycling. J Power Sources 2004;137:134-9.

European Commission. Integrated Pollution Prevention and Control (IPPC);Reference Document on best available techniques in the non ferrous metals industries. Report by European IPPC Bureau at the Institute for Prospective Technological Studies, Sevilla, Spain; 2001

European Commission. Integrated Pollution Prevention and Control (IPPC); Reference Document on best available techniques for the manufacture of large volume inorganic chemicals - ammonia, acids and fertilisers. Report by European IPPC Bureau at the Institute for Prospective Technological Studies, Sevilla, Spain; 2007.

Fenton MD. Mineral commodity summaries-iron and steel scrap. U S Geol Surv 2008:88-9.

Ferracin LC, Cha'con-Sanhueza AE, Davoglio RA, Rocha LO, Caffeu DJ, Fontanetti AR, et al. Lead recovery from a typical Brazilian sludge of exhausted lead-acid batteries using an electrohydrometallurgical process. Hydrometallurgy 2002;65:137-44.

Freeman H, Harten T, Springer J, Randall P, Curran MA, Stone K. Industrial pollution prevention: a critical review. J Waste Manage 1992;42:618-56.

Frias C, Diaz G, Ocana N, Lozano JI. Silver, gold and lead recovery from bioleaching residues using the PLINT process. Miner Eng 2002;15:877-8.

Gearhart J. Menke D, Griffith C, Mills K. Getting the lead out: impacts of and alternatives for automotive lead uses. Environmental Defense, Ecology centre; 2003. Accessed on 8/ 20/2008 at http://www.ecocenter.org/publications/downloads/GettingLeadOut.pdf.

Genaidy AM, Sequeira R, Tolaymat T, Kohler J, Rinder M. An exploratory study of lead recovery in lead-acid battery lifecycle in US market: an evidence-based approach. Sci Total Environ 2008;407(1):7-22.

Hanson Westhouse. Finders resources limited. Final approach. marketing communication; 2008. p. 1-19. Accessed on June 302008 at www.hansonwesthouse.com.

Hilson G. Barriers to implementing cleaner technologies and cleaner production (CP) practices in the mining industry: A case study of the Americas. Miner Eng 2000;13 (7):699-717.

Hilson G. Defining "cleaner production" and "pollution prevention" in the mining context. Miner Eng 2003;16:305-21.

Hossain KA, Khan FI, Hawboldt K. Sustainable development of process facilities: state-ofthe-art review of pollution prevention frameworks. J Hazard Mater 2008:150:4-20.

Hughes S. Applying Ausmelt technology to recover $\mathrm{Cu}$, Ni, and Co from slags. J Miner 2000:30-4.

Jaworek A, Balachandran W, Krupa A, Kulon J, Lackowski M. Wet electroscrubbers for state of the art gas cleaning. Environ Sci Technol 2006;40(20):6197-208.

Jolly R, Rhin C. The recycling of lead-acid batteries: production of lead and polypropylene. Resour Conserv Recyc 1994;10:137-43.

Kang HY, Schoenung JM. Electronic waste recycling: a review of U.S. infrastructure and technology options. Resour Conserv Recyc 2005;45:368-400.

Kenson R. Recovering valuable chemicals from air emissions. Environmental experts; 2005. Accessed on June 52008 at http://air.environmental-expert.com.

Kinaev NN, Jak E, Hayes PC. Kinetics of reduction of lead smelting slags with solid carbon. Scand J Metall 2005;34:150-7.

Kreusch MA, Ponte MJJS, Ponte HA, Kaminari NMS, Marino CEB, Mymrin V. Technological improvements in automotive battery recycling. Resour Conserv Recyc 2007;52:368-80. 
Legislature of the State of Idaho. House bill no. 611 by Environmental Affairs Committee; 2004. Accessed June14 at http://www3.state.id.us/oasis/2006/ H0611.html.

Lewis AE, Beautement C. Prioritizing objectives for waste reprocessing: a case study in secondary lead refining. Waste Manage 2002;22:677-85.

Lyakov NK, Atanasova DA, Vassilev VS, Haralampiev GA. Desulphurization of damped battery paste by sodium carbonate and sodium hydroxide. J Power Sources 2007:171:960-5.

Matheickal JT, Yu Q. Biosorption of lead (II) from aqueous solutions by Phellinus Badius. Miner Eng 1997;10(9):947-57.

Mesina MB, De Jong TPR, Dalmijn WL. Automatic sorting of scrap metals with a combined electromagnetic and dual energy X-ray transmission sensor. Int J Miner Process 2007;82:222-32.

Missouri Air Conservation Commission. The Doe Run Company - Buick resource recycling facility, Project no.2001-10-058. Department of natural resources, state of Missouri; 2005. Accessed on June 152008 at http://www.epa.gov/region07/.

Mooiman MB, Sole KC, Kinneberg DJ. Challenging the traditional hydrometallurgy curriculum-an industry perspective. Hydrometallurgy 2005;79:80-8.

Moors EHM, Mulder KF, Vergragt PJ. Towards cleaner production: barriers and strategies in the base metals producing industry. J Clean Prod 2005;13:657-68.

Moss LR. Local governments reduce costs through pollution prevention. J Clean Prod 2008:16:704-8

Nakada H, Mihara N, Kawaguchi Y, Osada S, Kuchar D, Matsuda H. Volatilization behavior of lead from molten slag under conditions simulating municipal solid waste melting. J Mater Cyc Waste Manage 2008;10:19-23.

Olson D. Mineral commodity summaries-gypsum. U S Geol Surv 2008:76-7.

Olympia Resource Limited. Keysbrook Mineral Sands Project Bankable Feasibility Study; 2005. p. 2-9.

PT Seman Pandang. Energy efficiency guide for industry in Asia; 2006. Accessed on 6/20/2208 at http://www.energyefficiencyasia.org/.

Quirijnen L. How to implement efficient local lead-acid battery recycling. J Power Sources 1999;78:267-9.

Rabah MA. Combined hydro-pyrometallurgical method for the recovery of high lead/ tin/bronze alloy from industrial scrap. Hydrometallurgy 1998;47:281-95.

Rabah MA, Barakat MA. Energy saving and pollution control for short rotary furnace in secondary lead smelters. Renew Energy 2001;23:561-77.

Raghavan R, Mohanan PK, Swarnkar SR. Hydrometallurgical processing of lead-bearing materials for the recovery of lead and silver as lead concentrate and lead metal. Hydrometallurgy 2000;58:103-16.

Ramus K, Hawkins P. Lead/acid battery recycling and the new Isasmelt process. J Power Sources 1993;42:299-313.

Reddy RG. Emerging technologies in extraction and processing of metals. Metall Mater Trans 2003;34B:137-53.

Reuter M, Sudholter S, Kruger J. Some criteria for the selection of environmentally acceptable processes for the processing of lead- and zinc-containing flue dusts. J S Afr Inst Min Metall 1997:27-42.

Ryzhenkov AN, Yaroshevskii SL, Zamuruev VP, Popov VE, Afanas'eva ZK. Study of a blastfurnace smelting technology which involves the injection of pulverized-coal fuel, natural gas, and an oxygen-enriched blast into the hearth. Metallurgist 2006;50:5-6.

Saman N, Nutter D. Energy conservation through improved industrial ventilation in small and medium-sized industrial plants. 16th annual industrial energy technol- ogy conference; 1994. Accessed on June 102008 at http://txspace.tamu.edu/ bitstream/handle/1969.1/2477/ESL-PA-94-04-03.pdf.

Scott K, Chen X, Atkinson JW, Todd M, Armstrong RD. Electrochemical recycling of tin, lean and copper from stripping solution in the manufacture of circuit boards. Resour Conserv Recyc 1997;20:43-55.

Smith G. Mineral commodity summaries-lead. U S Geol Surv 2008:94-5.

Socolow R, Thomas V. The industrial ecology of lead and electric vehicles. J Ind Eco 1997; 1(1):13-37.

Salomone R, Mondello F, Lanuzza F, Micali G. Environmental assessment an eco-balance of a recycling plant for spent lead-acid batteries. Environ Manage 2005;35(2):206-19.

Tianjun Y, Qichang W. High efficiency and long campaignship blast furnace for the 21st century. Scand J Metall 1999;28:70-6.

US Environmental Protection Agency (USEPA). AP 42, Fifth edition, Compilation of air pollutant emission factors, Volume 1: Stationary point and area sources; 1995 Accessed on 6/20/2008 at http://www.epa.gov/ttn/chief/ap42/.

US Environmental Protection Agency (USEPA). Locating and estimating air emissions from sources of lead and lead compounds. Research Triangle Park, NC: Office of Air Quality Planning and Standards; 1998. Accessed on 3/25/2008 at http:// www.epa. gov/ttn/chief/le/lead.pdf.

United Nations Environment Program (UNEP). Environmental technology assessment (EnTA) Workshop Report. Manila, Republic of the Philippines; 2000. http://www. mineralresourcesforum.org/docs/pdfs/EnTAReport.pdf. Accessed on 5/14/2008.

United Nations Environment Program (UNEP). Technical guidelines for the environmentally sound management of waste lead-acid batteries. Secretariat of the Basel Convention; 2003.

Vaysgant Z, Morachevsky A, Demidov A, Klebanov E. A low-temperature technique for recycling lead/acid battery scrap without wastes and with improved environmental control. J Power Sources 1995;53:303-6.

van Schaik A, Reuter MA. The time-varying factors influencing the recycling rate of products. Resour Conserv Recyc 2004;40:301-28.

Warhurst A, Bridge G. Improving environmental performance through innovation: recent trends in the mining industry. Miner Eng 1996;9(9):907-21.

Warner AEM, Diaz CM, Dalvi AD, Mackey PJ, Tarasov AV. JOM world nonferrous smelter survey, part III: Nickel: Laterite. J Miner 2006;58(4):11-20.

Wernick IK, Themelis NJ. Recycling metals for the environment. Annu Rev Energy Environ 1998;23:465-97.

Wolters R, Wendler B, Schmidt B, Holdinghausen A, Prade H. Rinsing water recovery in the steel industry - a combined UF/NF treatment. Desalination 2008;224:209-14.

Xstrata. Mount Isa mines sustainability report; 2006. Accessed on 6/20/2008 at http:/ / www.xstrata.com/assets/pdf/xcu_sus_\%20mountisa_2006.en.pdf.

Yender GL. Battery recycling technology and collection process. Electronics and the Environment, 1998. Proceedings of the 1998 IEEE International Symposium; 1998 p. 30-5.

Zabaniotou A, Kouskoumvekaki E, Sanopoulos D. Recycling of spent lead:acid batteries: the case of Greece. Resour Conserv Recyc 1999;25:301-17.

Zhang Y, Barr PV, Meadowcroft TR. Continuous scrap melting in a short rotary furnace. Miner Eng 2008;21:178-89.

Zhao B, Errington B, Jak E, Hayes P. Gaseous reduction of ISASMELT lead slag and lead blast furnace sinters. Lead Zinc 2008:133-46.

Ziebik A, Stanek W. Influence of blast-furnace process thermal parameters on energy and exergy characteristics and exergy losses. Int J Energy Res 2006;30:203-19. 